\title{
Copper-based Reactions in Analyte-Responsive Fluorescent Probes for Biological Applications
}

\author{
Ho Yu Au-Yeung*, Chung Ying Chan, Ka Yan Tong and Zuo Hang Yu \\ Department of Chemistry, The University of Hong Kong, Pokfulam Road, Hong Kong, P. R. \\ China
}

Email: hoyuay@hku.hk; (852)-22194697

\begin{abstract}
Copper chemistry has been capitalized on in a wide spectrum of biological events. The central importance of copper in biology lies in the diverse chemical reactivity of the redoxactive transition metal ranging from electron transfer, small molecule binding and activation, to catalysis. In addition to its many different roles in natural biological systems, the diverse chemical reactivity of copper also represents a rich opportunity and resource to develop synthetic bioanalytical tools for the study of biologically important species and molecules. In this mini-review, fluorescent probes featuring a specific copper-based chemical reaction to selectively detect a biologically relevant analyte will be discussed. In particular, fluorescent probes for sensing labile copper ions, amino acids and small reactive species will be highlighted. The chemical principles, advantages and limitations of the different types of copper-mediated chemical reactions in these fluorescent probes will be emphasized.
\end{abstract}

\section{Introduction}

Copper is an essential trace element to living organisms [1, 2]. Largely in the form of coppercontaining enzymes and proteins, the transition metal is important in many biological functions including oxygen transport, respiration, electron transfer, small molecule activation, substrate oxidation, and signal transduction. Under physiological conditions, the redox-active transition metal is mainly in its cuprous $\mathrm{Cu}(\mathrm{I})$ and cupric $\mathrm{Cu}(\mathrm{II})$ states which can coordinate to a range of nitrogen- and sulfur-based ligands. It is perhaps the unique combination of its redox potency, Lewis acidity and coordination properties that renders copper of central importance in biology. On the other hand, the same diverse chemical reactivity of copper also represents a great opportunity for chemists to devise new synthetic chemical tools to study and better understand how different chemical species play their roles in complex biological systems.

Molecular imaging using analyte-responsive fluorescent probes to visualize biological processes at the molecular level has recently emerged as a highly efficient tool for the study of metal ions, reactive species and biomolecules in live biological samples [3, 4]. Two approaches, binding-based and reaction-based (Figure 1), are commonly used in the development of these luminescent probes $[3,5,6]$. In the binding-based approach, emission properties of the probe change upon a reversible, non-covalent binding of the target to result in an optical signal. Selectivity of the probe is achieved by the host-guest complementarity between the recognition unit of the probe and the analyte of interest. Designing a selective 
host for recognition is not trivial, especially when the target analyte shares similar size, shape, surface potential or functional groups for non-covalent interactions with other competitive biomolecules. In the reaction-based approach, the optical readout is a result of a chemical transformation of the probe by the target. Specificity of the chemical reaction determines the selectivity of the fluorescent probe. In this mini-review, we will discuss several different strategies that exploit the unique and diverse chemical reactivity of copper for developing analyte-selective fluorescent probes for biologically important ions and molecules. The chemical basis in the design and working principle of these luminescent probes will be highlighted to demonstrate how the diverse chemical properties of copper can be exploited in the development of these useful bioanalytical reagents.

(a)

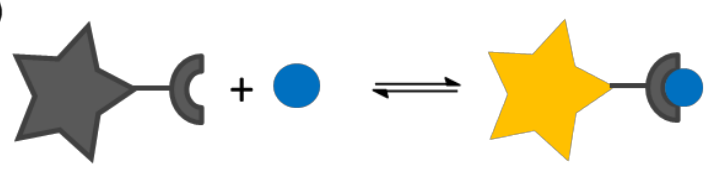

(b)

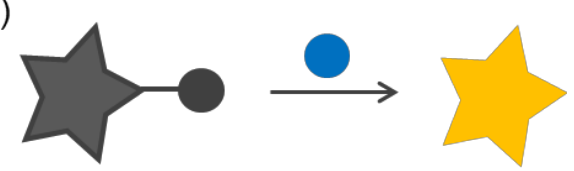

Figure 1. Schematic representation of (a) binding-based and (b) reaction-based approaches to analyte-selective fluorescent probes. A reversible binding or a chemical transformation changes the emission properties of the probe to result in an optical signal.

\section{Luminescent Probes for Labile Copper}

In addition to the non-exchangeable copper coordinated tightly in protein active sites, the intracellular labile copper pool which can undergo dynamic ligand exchange has attracted much recent attention [7]. The redox activity of the labile copper has been associated with the generation of reactive oxygen species (ROS), cellular redox balance and immune response. Recent studies also reveal the possible involvement of labile copper in neuronal activity $[8,9]$ and signaling glucose metabolism [10, 11]. For example, a recent study has demonstrated that copper can modulate cyclic adenosine monophosphate signaling and regulate lipolysis through inhibition of the phosphodiesterase PDE3B [12]. To aid in studying the roles of labile copper in these physiological processes, various copper-selective luminescent probes that can provide direct spatiotemporal information on the transition metal in living cells and/or animals have been developed. The development of synthetic luminescent probes for the study and biological imaging of copper has been reviewed in detail in several articles $[5,13,14]$. In this section, different types of chemical reactions and strategies used in selective copper sensing are discussed. In particular, exploitation of the chemical properties of $\mathrm{Cu}(\mathrm{I})$ and $\mathrm{Cu}(\mathrm{II})$ for the development of copper probes specific for these oxidation states are highlighted.

Due to the reducing environment in eukaryotic cells, the majority of intracellular labile copper exists as $\mathrm{Cu}(\mathrm{I})$. Copper sensors for cell imaging are therefore designed to target specifically $\mathrm{Cu}(\mathrm{I})$ over $\mathrm{Cu}(\mathrm{II})$, in addition to the selectivity against other common transition metals. Both binding-based and reaction-based approaches have been exploited to develop luminescent probes for the selective detection of $\mathrm{Cu}(\mathrm{I})$ in biological samples. On the other hand, $\mathrm{Cu}(\mathrm{II})$ is more dominant in the extracellular environment and has been implicated in a number of neurodegenerative diseases such as Alzheimer's disease $[15,16]$. As the open-shell Cu(II) 
is a potent fluorescence quencher, most of the reported turn-on $\mathrm{Cu}(\mathrm{II})$ probes are reactionbased.

Binding-based $\mathrm{Cu}(\mathrm{I})$ probes. A large number of binding-based luminescent sensors for $\mathrm{Cu}(\mathrm{I})$ have been developed using the selective binding of $\mathrm{Cu}(\mathrm{I})$ to multidentate thioether ligands. Considering the Hard-Soft-Acid-Base principle, the soft $\mathrm{Cu}(\mathrm{I})$ can be easily discriminated by the soft sulfur donors from other common biogenic main group (e.g. $\mathrm{Na}^{+}, \mathrm{K}^{+}, \mathrm{Mg}^{2+}$ and $\mathrm{Ca}^{2+}$ ) and transition metals (e.g. $\mathrm{Fe}^{2+}, \mathrm{Fe}^{3+}$, and $\mathrm{Zn}^{2+}$ ) which are hard to borderline Lewis acids. Further $\mathrm{Cu}(\mathrm{I})$ selectivity over other soft metal ions (e.g. $\mathrm{Hg}^{2+}$ and $\mathrm{Pb}^{2+}$ ) may be achieved by a judicious choice in the size, geometry and donor number of the ligands. Fluorescent $\mathrm{Cu}(\mathrm{I})$ probes were obtained by coupling these thioether ligands with a fluorescent reporter whose emission properties can be modulated upon $\mathrm{Cu}(\mathrm{I})$-coordination through photo-induced electron transfer, internal charge transfer or other mechanisms [14]. CTAP (copperresponsive triarylpyrazoline) reported by Fahrni and co-workers, and the CS (opper sensor) series from the Chang group are representative examples of $\mathrm{Cu}(\mathrm{I})$ selective fluorescent probes. Upon coordination of $\mathrm{Cu}(\mathrm{I})$ by the aminothioether ligand in these probes, photo-induced electron transfer from the amine lone-pair electron is quenched, thus restoring emission from the fluorophore. Labile $\mathrm{Cu}(\mathrm{I})$ in the biological samples is detected by a fluorescence turn-on response. With the pyrazoline-based CTAP-1 and the more hydrophilic CTAP-2 (Figures 2a and 2b), Farhni and co-workers revealed copper localization in the mitochondria and Golgi in NIH 3T3 cells and demonstrated the in-gel detection of protein-bound copper in Atox1 (Antioxidant Protein 1) $[17,18]$. Using the BODIPY (borondipyrromethene)-based CS1 and CS3 (Figures 2c and 2d), Chang and co-workers observed an increase in intracellular copper in live human embryonic kidney (HEK) cells upon copper enrichment and a calcium-dependent redistribution of labile copper in neurons respectively $[19,20]$. Since then, a whole series of copper probes has been developed following a similar $\mathrm{Cu}(\mathrm{I})$ binding strategy with individual probes displaying various photophysical and organelle labeling properties [7, 21-29]. For example, the ratiometric copper sensor RCS1 can visualize the ascorbate-induced release of endogenous $\mathrm{Cu}(\mathrm{I})$ in HEK293T and C6 rat glioma cells through a ratiometric response (Figure 2e) [21]. The mitochondria-targeting copper sensor, Mito-CS1, has been applied to study the level of mitochondrial copper in fibroblasts from patients with mutations in the proteins SCO1 and SCO2 (synthesis of cytochrome c oxidase) (Figure 2f) [23]. Two rhodol-based copper probes, having improved hydrophilicity, have been used to image the labile copper pool in neurons to demonstrate the role of the metal in modulating neural circuit activity (Figure $2 \mathrm{~g}$ ) [25]. In addition to live cell imaging, by changing the imaging modality on these $\mathrm{Cu}(\mathrm{I})$ probes, copper can also be imaged in tissues and live animals. Using a near-IR cyanine fluorophore, Chang and co-workers have developed a copper probe for the in vivo imaging of copper in a murine Wilson disease model in transgenic mice (Figure 2h) [26]. A two-photon copper fluorescent probe reported by Cho and co-workers has been shown to be able to detect $\mathrm{Cu}(\mathrm{I})$ in fresh hippocampal tissue slices at a depth of 90-220 $\mu \mathrm{m}$ (Figure 2i) [27]. 

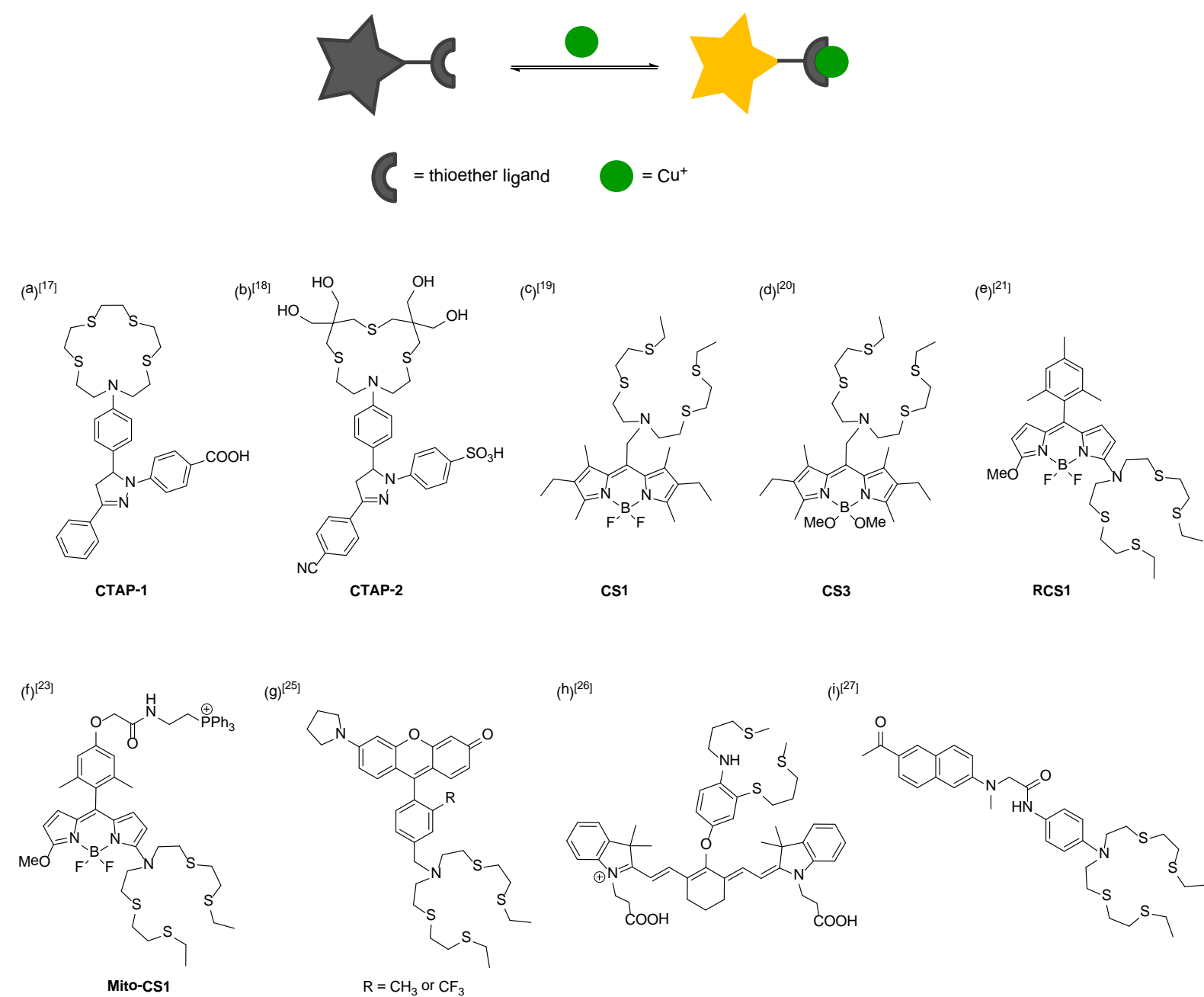

Figure 2. Examples of binding-based $\mathrm{Cu}(\mathrm{l})$ probes.

Since the fluorescence response from these binding-based $\mathrm{Cu}(\mathrm{l})$ probes is a result of the reversible binding of $\mathrm{Cu}(\mathrm{I})$ to the probes, one advantage of such probes is that the level of labile copper could be monitored in a time-dependent manner to track the changes in the level of labile copper over time. However, the relative binding strengths and dynamic copper equilibrium between the thioether ligands of the probes and the bioligands constituting the "labile copper pool" will need careful characterization and consideration to help address the role of the "labile copper pool" in the biological system being studied. Currently, "labile copper" broadly refers to chelatable copper with no well-defined dissociation constants. With the different molecular structures (e.g. macrocyclic vs acyclic) and donor combinations of the thioether ligands, the $\mathrm{Cu}(\mathrm{l})$ probes discussed above have different $\mathrm{K}_{\mathrm{d}}$ values ranging from $10^{-14}$ to $10^{-11} \mathrm{M}[14,30]$. With the $\mathrm{K}_{\mathrm{d}}$ values for copper binding proteins and glutathione (GSH) ranging from $10^{-15}$ to $10^{-12} \mathrm{M}[30]$, the use of these different $\mathrm{Cu}(\mathrm{l})$ probes may lead to a different definition of "labile copper" when applied in different cell types or biological systems. In addition, considering that $\mathrm{Cu}(\mathrm{I})$ can adopt coordination numbers from 2 to 4 , the denticity of the thioether ligands in these $\mathrm{Cu}(\mathrm{I})$ probes could vary and the assumption of a simple copper equilibrium involving only the bioligand/protein and the probe may not always be true. It is possible that a ternary protein $/ \mathrm{Cu}(\mathrm{l}) / \mathrm{probe}$ complex, especially for bioligands/proteins with a kinetically accessible copper binding site, could also give a 
fluorescence response. Careful interpretation of the fluorescence data will be necessary to extract useful biological information.

Reaction-based $\mathrm{Cu}(\mathrm{I})$ probes. The rich chemical activity of $\mathrm{Cu}(\mathrm{I})$ has also been exploited to develop $\mathrm{Cu}(\mathrm{I})$ fluorescent sensors. One example of copper-based reactions for developing selective copper sensors is the $\mathrm{Cu}(\mathrm{I})$-catalyzed azide-alkyne cycloaddition. Viguier and Hulme have reported an alkyne-functionalized Eu(III) complex linked with an azideappended dansyl antenna to induce energy transfer and result in a luminescent response [31]. Formation of the antenna-Eu(III) complex conjugate using a biologically relevant $\mathrm{Cu}(\mathrm{I})$ glutathione complex was found to result in a 10-fold luminescence enhancement.

Another example is the copper-mediated biomimetic oxidative bond cleavage in the fluorescein-tris(2-picolylamine) conjugates, FluTPA1 and FluTPA2, reported by Taki and coworkers (Figure 3) [32]. In FluTPA1 and FluTPA2, the fluorescein fluorophores are alkylated by the TPA ligand through the phenolic oxygen to yield a non-emissive form. In the presence of $\mathrm{Cu}(\mathrm{I})$, metal coordination followed by $\mathrm{O}_{2}$-activation at the copper centre resulted in an oxidative $\mathrm{C}-\mathrm{O}$ bond cleavage to release the fluorophore, which in-turn produced a fluorescence turn-on response to report level of labile $\mathrm{Cu}(\mathrm{I})$ in live $\mathrm{HeLa}$ (human cervix epitheloid carcinoma) cells. As the $\mathrm{C}-\mathrm{O}$ bond cleavage requires a specific copper-mediated $\mathrm{O}_{2}$ reactivity, good $\mathrm{Cu}(\mathrm{I})$ selectivity over $\mathrm{Cu}(\mathrm{II})$ and other metal ions including $\mathrm{Mn}(\mathrm{II}), \mathrm{Fe}(\mathrm{II})$, $\mathrm{Co}(\mathrm{II}), \mathrm{Ni}(\mathrm{II})$ and $\mathrm{Zn}(\mathrm{II})$ is achieved. By coupling the biomimetic TPA ligand onto a triphenylphosphonium-appended rhodol fluorophore, Taki and co-workers have reported a mitochondria-targeting $\mathrm{Cu}(\mathrm{I})$ fluorescent probe to visualize mitochondrial copper in live HeLa cells [33]. Further extending the biomimetic strategy, Chang and co-workers have recently prepared a TPA-derived, copper caged luciferin, CCL-1, for the in vivo bioluminescent imaging of labile copper in a murine model of non-alcoholic fatty liver disease in transgenic mice [34]. In addition, modifying the biomimetic ligand to tune the metal- $\mathrm{O}_{2}$ reactivity in the oxidative bond cleavage gives $\mathrm{Fe}(\mathrm{II})$ - and $\mathrm{Co}(\mathrm{II})$-selective fluorescent probes [35, 36]. Unlike the reversible binding-based probes, these reaction-based probes are irreversible and only provide snapshots of the copper level of the sample at a single time point. However, such irreversible bond cleavage can drive the copper equilibrium towards the probe and in principle could capture any kinetically accessible copper in the biological sample. Of course, the fluorescent signal observed will also be dependent on the kinetics of the reaction/chemical step that produces the fluorescent molecule, and such kinetic properties of the probe will need to be taken into consideration when designing the biological experiments that use the probe. The definition of "labile copper" that can be detected by these reactionbased probes again needs careful attention. 


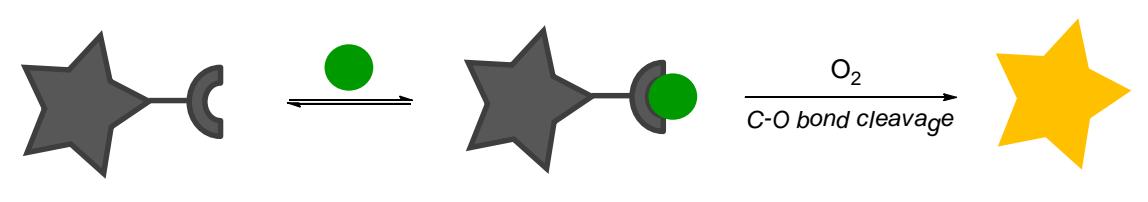

$=\operatorname{tris}(2-p y r i d y l)$ amine ligand $O=\mathrm{Cu}^{+}$

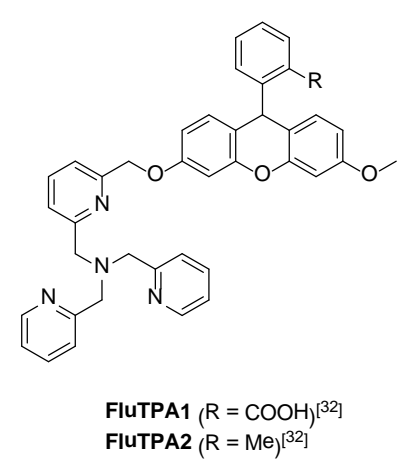

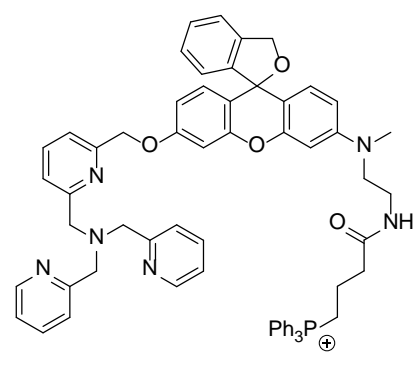

RdITPA-TPP[33]

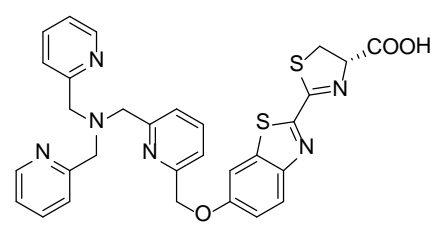

CCL-1 $\left.{ }^{34}\right]$

Figure 3. Examples of reaction-based fluorescent and bioluminescent $\mathrm{Cu}(\mathrm{I})$ probes. Upon binding of $\mathrm{Cu}(\mathrm{I})$ to the TPA ligand, an oxidative $\mathrm{C}-\mathrm{O}$ bond cleavage reaction releases the active luminescent reporter.

Reaction-based Cu(II) probes. A common strategy in reaction-based $\mathrm{Cu}$ (II) sensing is based on the Lewis acid-catalyzed hydrolysis of hydrazides [37, 38], esters [39, 40], lactones [41], lactams [42, 43] and amides [44]. The hydrolysis of these probes to yield a fluorescence response is usually assisted by $\mathrm{Cu}(\mathrm{II})$, which coordinates to the carbonyl group and an additional donor, which may also provide metal selectivity. Czarnik and co-workers first reported a rhodamine hydrazide derivative which is non-emissive in its ring-closed spirolactam form (Figure 4a) [42]. In the presence of $\mathrm{Cu}$ (II) in aqueous medium, the colourless solution turns pink with a concomitant fluorescence enhancement due to a $\mathrm{Cu}$ (II)catalyzed hydrazide hydrolysis. Using a similar strategy, Yoon and co-workers reported a rhodamine hydrazone appended with a boronic acid to assist in $\mathrm{Cu}$ (II) binding prior to the hydrolysis (Figure 4b) [45]. The probe has been applied in the imaging of copper in P19 (mice embryonic teratocarcinma) cells and zebrafish. A more recent example from Chan and co-workers is based on the $\mathrm{Cu}(\mathrm{II})$-catalyzed hydrolysis of 2-picolinic ester for the ratiometic photoacoustic imaging of the transition metal (Figure 4c). Ability of the probe to image $\mathrm{Cu}(\mathrm{II})$ in $\mathrm{cm}$ range has been demonstrated in both tissue phantom and chicken breast tissue [46]. 


\section{*. - \\ - hydrolyzable group $\quad=\mathrm{Cu}^{2+}$}
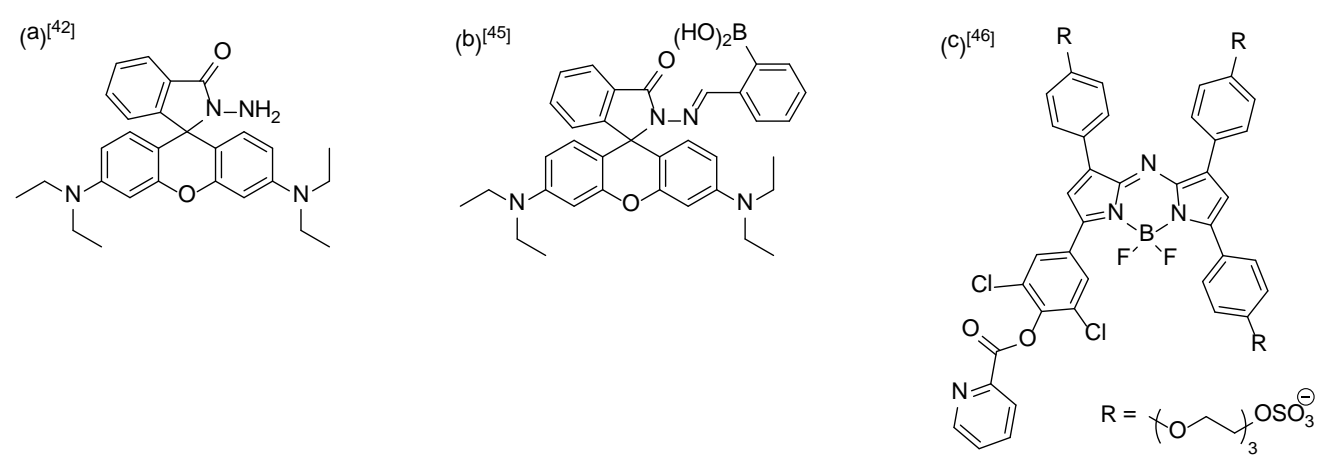

Figure 4. Examples of $\mathrm{Cu}(\mathrm{II})$ fluorescent probes with a $\mathrm{Cu}(\mathrm{II})$-assisted hydrolysis mechanism.

Reaction-based $\mathrm{Cu}$ (II) probes based on copper-mediated oxidation have also been reported. Shiraishi and co-workers have reported a BODIPY derivative which is non-fluorescent due to electron transfer from the amine nitrogen to the BODIPY excited state (Figure 5a) [47]. Upon binding of $\mathrm{Cu}(\mathrm{II})$ to the $\mathrm{N}, \mathrm{O}$-chelating ligand, a copper-mediated oxidative dehydrogenation leads to the formation of a $\mathrm{Cu}(\mathrm{I})$-Schiff base complex and results in a fluorescence enhancement. Lin and co-workers have reported a non-fluorescent dihydrorosamine which can be oxidized by $\mathrm{Cu}(\mathrm{II})$ to the fluorescent rosamine (Figure 5b) [48]. The dihydrorosamine oxidation is selective only to $\mathrm{Cu}$ (II) but not other common transition metal ions such as $\mathrm{Fe}(\mathrm{II})$, $\mathrm{Fe}(\mathrm{III}), \mathrm{Co}(\mathrm{II}), \mathrm{Ni}(\mathrm{II})$ and $\mathrm{Zn}(\mathrm{II})$. The probe has been applied in the imaging of intracellular copper in live nasopharyngeal carcinoma cells. An $\mathrm{O}_{2}$-dependent oxidative bond cleavage reaction mediated by $\mathrm{Cu}$ (II) has been utilized by Bai and co-workers to develop the $\mathrm{Cu}$ (II)selective fluorescence turn-on probe (Figure 5c) [49]. Similar to FluTPA1, the Cu(II) probe contains a fluorescein derivative alkylated with a tridentate NNO imine ligand. Upon coordination to $\mathrm{Cu}(\mathrm{II})$ by the ligand, an $\mathrm{O}_{2}$-dependent oxidative bond cleavage reaction releases the fluorophore which subsequently converts into its fluorescent form. The fluorescence response is selective to $\mathrm{Cu}$ (II) over other first row transition metal ions and the probe has been applied in the imaging of copper in live HeLa cells. 

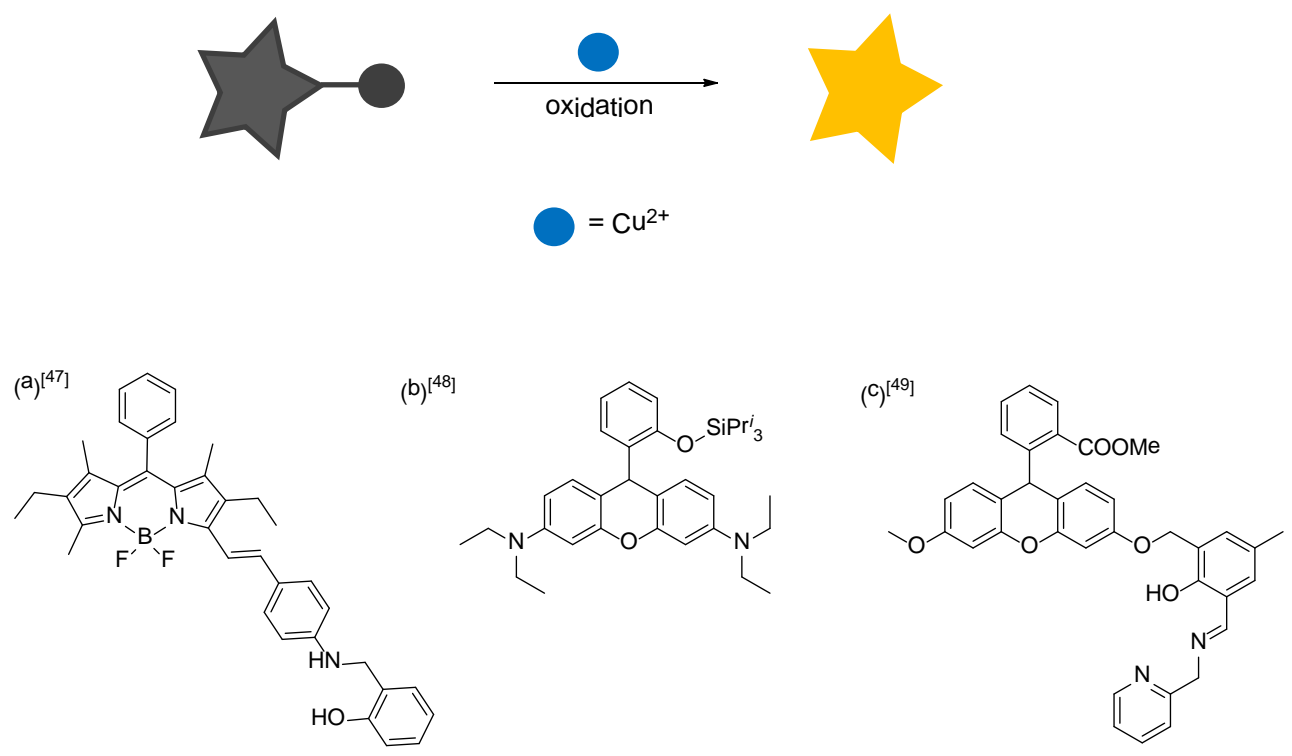

Figure 5. Examples of reaction-based $\mathrm{Cu}(\mathrm{II})$ probes with a $\mathrm{Cu}(\mathrm{II})$-mediated oxidation mechanism.

Comparing the $\mathrm{Cu}(\mathrm{II})$ probes based on $\mathrm{Cu}(\mathrm{II})$-catalyzed hydrolysis and $\mathrm{Cu}(\mathrm{II})$-mediated oxidation, different strategies are employed to attain $\mathrm{Cu}$ (II) selectivity. For $\mathrm{Cu}(\mathrm{II})$-catalyzed hydrolysis, additional ligand donors that preferentially coordinate to $\mathrm{Cu}$ (II) are incorporated in the probe to distinguish $\mathrm{Cu}$ (II) from other competing metal ions, which are also Lewis acidic, to provide metal selectivity. On the other hand, for probes based on $\mathrm{Cu}$ (II)-mediated oxidation, selectivity of the probe is dependent on the specificity of the oxidation, which in turn relates to the electronic properties of the metal. Although metal selectivity may be more easily achieved once a $\mathrm{Cu}(\mathrm{II})$-specific oxidation reaction has been identified, probe design and synthesis may not be trivial because the change in the covalent structure of the probe after oxidation will also have to result in a change in the fluorescent properties of the probe. Systematic variation of the photophysical properties of the probes may also not be straightforward.

\section{Luminescent Probes for Amino Acids}

Amino acids are the fundamental building blocks of proteins and are involved in numerous physiological processes including cell division, immune response and signal transduction $[50,51]$. A tight regulation on amino acid concentration is important for the normal functioning of the body and an imbalance in physiological amino acid concentrations can lead to diseases and abnormal physiological responses [52]. Many amino acids can act as effective ligands for metal coordination, and histidine (His), methionine (Met), cysteine (Cys), tyrosine (Tyr), glutamate (Glu) and aspartate (Asp) are indeed common biological ligands in the active sites of metalloproteins. Coordination chemistry exploiting specific interactions of amino acid and transition metal ion is therefore a popular strategy for developing luminescent probes for amino acids. 
Owing to its fast ligand exchange kinetics (solvent exchange rate $\approx 10^{7}-10^{9} \mathrm{~s}^{-1}$ at $25^{\circ} \mathrm{C}$ ) [53], Lewis acidity, borderline hardness, higher stability than other first row transition metals in the Irving-Williams series and other coordination properties, $\mathrm{Cu}(\mathrm{II})$ is one of the frequently used transition metal ions whose coordination with amino acids has been exploited in the design of amino acid probes. In particular, a considerable number of His and Cys probes based on $\mathrm{Cu}$ (II) coordination chemistry have been reported [54]. We will focus here on examples of these $\mathrm{Cu}$ (II)-based His and Cys probes and discuss the general strategy. Amino acid probes based on other metal ions and chemistry for their recognition and detection have been discussed in greater detail in other reviews $[50,55]$.

Cu(II)-based histidine probes. With the imidazole side chain having borderline Lewis acidity, His is a common biological ligand that is frequently found in active sites of metalloenzymes to coordinate with metal cofactors. The rich coordination chemistry of His towards metal ions offers a great opportunity for developing metal-based probes for its detection. For example, Qian and co-workers have reported a $\mathrm{Cu}$ (II) complex supported by a tetradentate aminopyridine ligand linked to a naphthaleneimide fluorophore, and demonstrated a Hisselective fluorescence enhancement by the $\mathrm{Cu}$ (II) complex (Figure 6) [56]. It is suggested that His acted as an additional ligand to coordinate to the $\mathrm{Cu}(\mathrm{II})$ and changed the pyridine-to$\mathrm{Cu}$ (II) ligand-to-metal charge transfer and the internal charge transfer of the naphthaleneimide that led to the fluorescence response. The complex ensemble has been applied in the imaging of intracellular His in live HeLa cells.

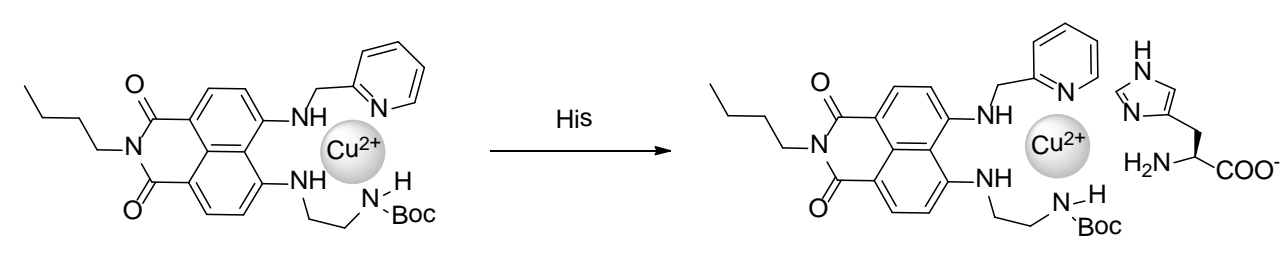

fluorescence at $537 \mathrm{~nm}$ quenched

fluorescence at $537 \mathrm{~nm}$ restored

Figure 6. A $\mathrm{Cu}(\mathrm{II})$ complex-fluorophore ensemble that gives a fluorescence turn-on response upon histidine coordination [56].

A closely related naphthaleneimide-based $\mathrm{Cu}(\mathrm{II})$ complex ensemble with a tetradentate nitrogen-based ligand has been reported by the same group as a His probe (Figure 7a) [57]. The complex ensemble has been shown to be selective to His against other amino acids including Cys, Met, Lys, Ser, Tyr, Asp and Glu. As demonstrated by HPLC analysis, the authors proposed that the fluorescence enhancement is due to a competitive coordination of $\mathrm{His}$ to $\mathrm{Cu}$ (II) that removes the paramagnetic quencher from the fluorophore. The $\mathrm{Cu}(\mathrm{II})$ complex ensemble has been used to detect His in live MCF-7 (human breast adenocarcinoma) cells and bovine serum albumin. A similar naphthaleneimide-based $\mathrm{Cu}(\mathrm{II})$ complex with a tetradentate aminopyridine ligand from $\mathrm{Xu}$ and co-workers also shows good selectivity to His over other amino acids, and has been applied in imaging His in both live HeLa cells and C. elegans (Figure 7b) [58]. On the other hand, Liang and co-workers have reported a peptide-based $\mathrm{Cu}$ (II) complex-fluorophore ensemble that shows a selective fluorescence turn-on by His over other amino acids (Figure 7c) [59]. A fluorescein derivative 
and a $\mathrm{Cu}(\mathrm{II})$-aminoquinoline complex were placed on the two ends of a peptide. The length of the peptide was carefully chosen to ensure fluorescence quenching of the fluorescein by the $\mathrm{Cu}(\mathrm{II})$ complex. Competitive $\mathrm{Cu}(\mathrm{II})$ binding by His removes the paramagnetic quencher and restores emission from the fluorescein. Good aqueous solubility and biocompatibility are provided by the peptide, and the complex ensemble has been applied in the imaging of intracellular His in live HepG2 (human hepatocyte carcinoma) cells.
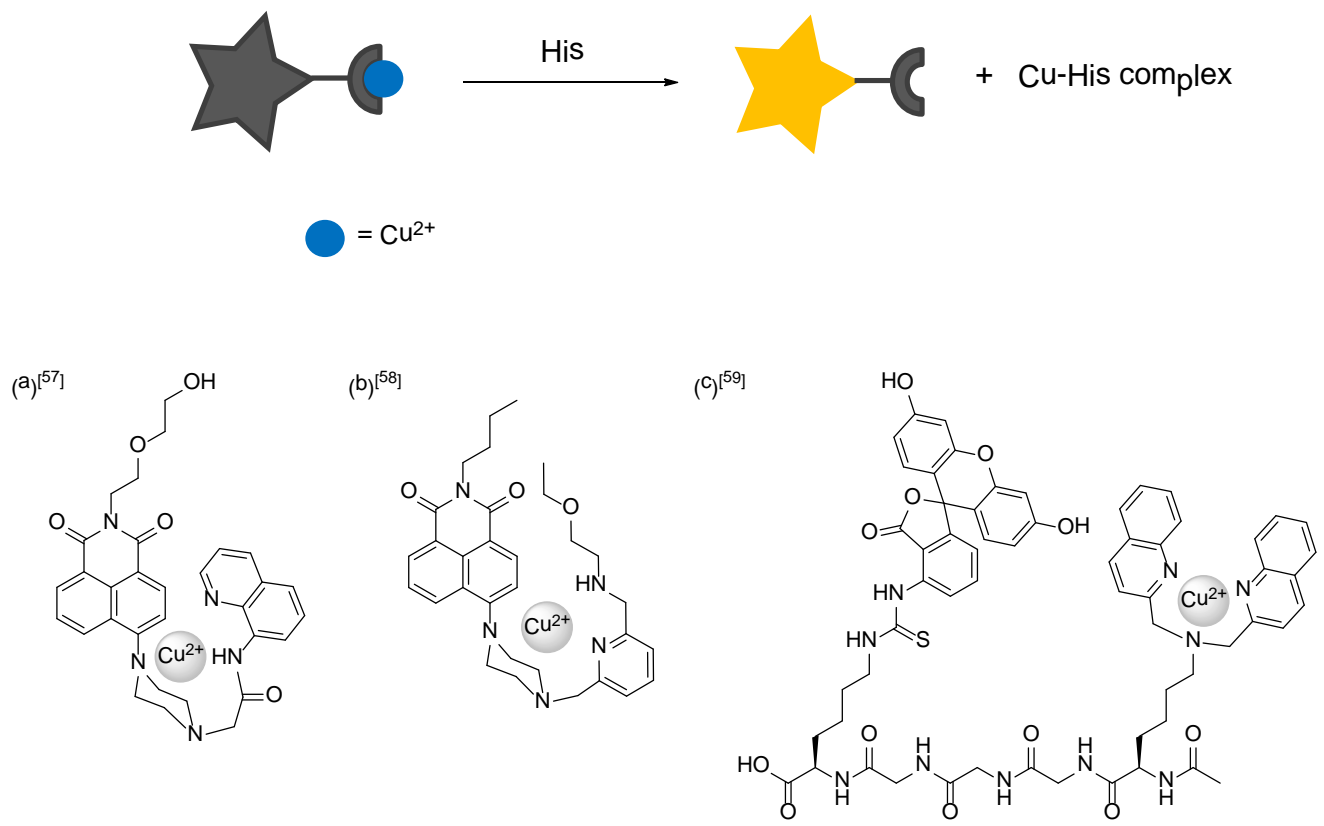

Figure 7. Examples of fluorescent His probes featuring a $\mathrm{Cu}(\mathrm{II})$ decomplexation mechansim.

In the above examples, selectivity of the probes towards His against other amino acids was all tested with equimolar amount of His and the competing amino acids at micromolar concentrations. While the $\mathrm{Cu}(\mathrm{II})$ in these probes showed a preferential coordination by His of borderline basicity over other hard (e.g. Ala, Try, Glu and Asp) and soft (e.g. Cys and Met) amino acids under the tested conditions, selectivity against GSH, which can be present in cells at millimolar level [60] and can also show competitive binding to $\mathrm{Cu}(\mathrm{II})$, was not tested. Indeed, a five-coordinate $\left[\mathrm{CuTpyCl}_{2}\right]$ (Tpy $=$ 2,6-terpyridine) complex which showed fluorescence enhancement upon formation of a ternary complex with His, fluorescence response can also be observed in the presence of other competitive ligands such as Cys [61].

Cu(II)-based cysteine probes. Cys is another common biological ligand that is found in the active sites of many metalloenzymes. The soft sulfur donor preferentially binds to soft metals like $\mathrm{Cu}(\mathrm{I})$. The highly nucleophilic thiol also distinguishes Cys from other amino acids, and indeed a significant number of Cys and biothiol probes have been designed based on this unique chemical reactivity $[62,63]$. Coordination of Cys to $\mathrm{Cu}(\mathrm{II})$ not only could displace the metal from the initial ligand, but could also reduce $\mathrm{Cu}(\mathrm{II})$ to $\mathrm{Cu}(\mathrm{I})$ with cysteine being oxidized to cystine [64, 65]. A number of fluorescent Cys probes have been designed based on this strategy. 
A study from Feng and co-workers showed that 1,1'-bi-2-naphthol (BINOL) can be oxidized by $\mathrm{Cu}(\mathrm{II})$ and the fluorescence of the oxidized BINOL was quenched by complexing with the $\mathrm{Cu}(\mathrm{II})$. It was found that in the presence of Cys, fluorescence of the oxidized BINOL was restored, which was proposed to be due to the removal of the paramagnetic $\mathrm{Cu}$ (II) from the oxidized BINOL by the thiol containing amino acid (Figure 8a) [66]. The fluorescence response is selective to Cys over other amino acids including His and Met, but GSH and homocysteine (Hcy) can also induce a fluorescence enhancement. Using a BODIPY-based Schiff-base $\mathrm{Cu}(\mathrm{II})$ complex, Shao and co-workers have demonstrated a Cys-dependent fluorescence enhancement in aqueous buffer (Figure 8b) [67]. The Cys detection mechanism is also proposed to be a Cys-mediated $\mathrm{Cu}$ (II) displacement, and the fluorescence turn-on is selective to Cys and Hcy over other amino acids. Other similar Cys probes based on $\mathrm{Cu}$ (II) displacement with other emissive groups have also been reported [68-71].

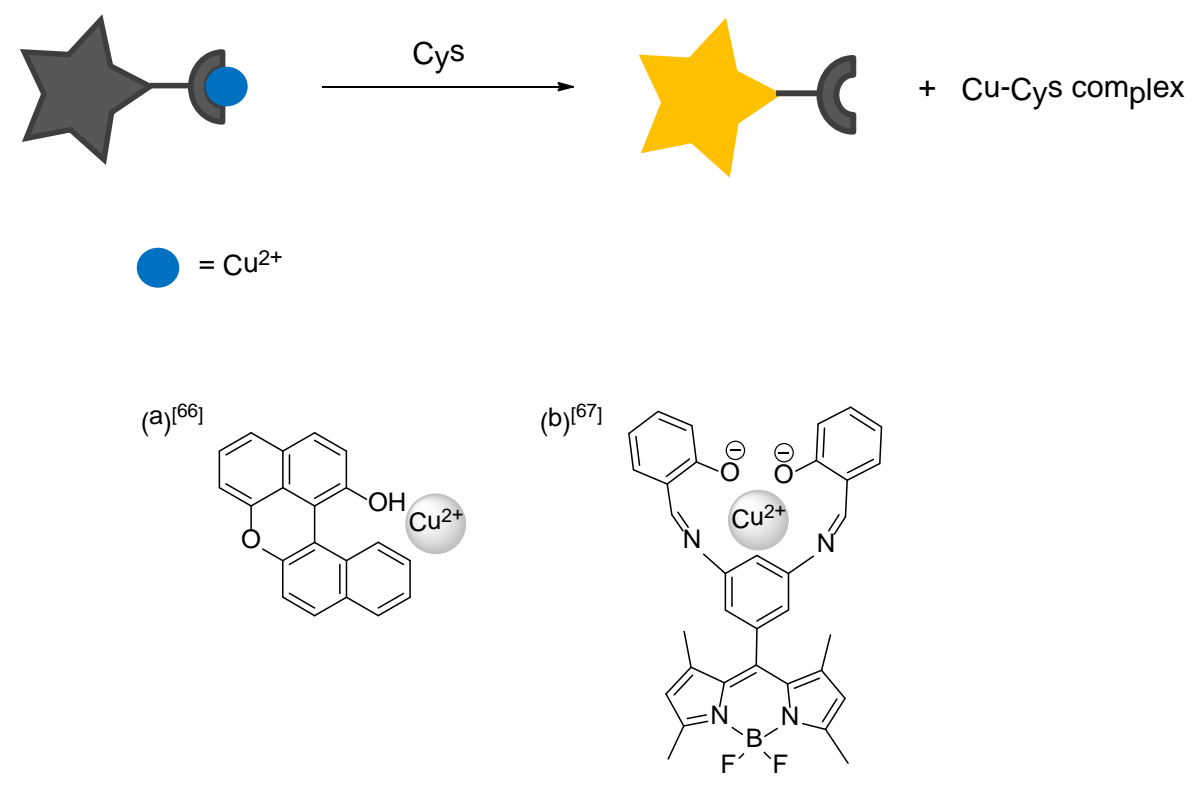

Figure 8. Examples of fluorescent Cys probes.

Due to the favourable copper coordination by His and Cys, some of $\mathrm{Cu}(\mathrm{II})$-based probes that utilized such $\mathrm{Cu}(\mathrm{II})$-decomplexation approach may give a dual response to both the amino acids. For example, Leung, Chan and co-workers have reported a $\mathrm{Cu}$ (II)-complexed coumarin-based fluorescent probe that shows fluorescence enhancement to His, Cys and biological thiols such as Hcy and GSH (Figure 9a) [72]. The $\mathrm{Cu}(\mathrm{II})$ complex ensemble consists of a coumarin fluorescent reporter whose fluorescence is quenched upon $\mathrm{Cu}$ (II) coordination via an $\mathrm{N}$-ethylmaleimide ligand. The probe can detect His in U87MG human glioblastoma cells pretreated with excess of thiol scavengers. Chattopadhyay, Das and coworkers have reported a dansyl derivative with two bis(2-picolyl)amine pendants and its dinuclear $\mathrm{Cu}$ (II) complex that gives a dual response to both His and Cys (Figure 9b) [73]. Two different detection mechanisms for His and Cys are proposed, in which His coordinates to the $\mathrm{Cu}$ (II) bis(2-picolyl)amine moiety in the probe, whereas Cys demetallates $\mathrm{Cu}$ (II) from the probe to result in the observed fluorescence response. The probe has been employed in 
the detection of Cys and His in human blood plasma and in the imaging of intracellular Cys in live human colon carcinoma Hct116 cells.
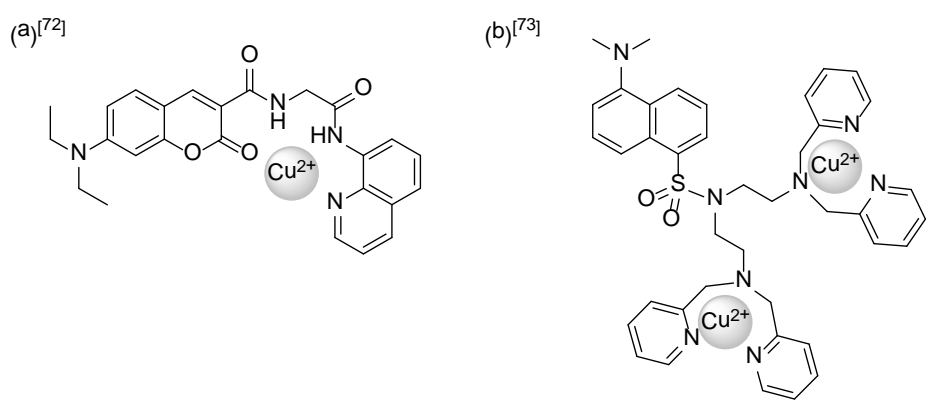

Figure 9. Examples of fluorescent probes that are responsive to both His and Cys.

Another type of copper-mediated reaction for the fluorescence Cys detection involves a $\mathrm{Cu}$ (II) demetallation followed by a hydrolysis of the ligand/probe. Kim and co-workers reported a $\mathrm{Cu}$ (II) complex ensemble of an iminocoumarin as a reaction-based probe for Cys (Figure 10) [74]. The iminocoumarin is non-fluorescent and acts as a tridentate ligand to coordinate to $\mathrm{Cu}(\mathrm{II})$, which stabilizes the imine from hydrolysis. In the presence of Cys, the thiol coordinates to the $\mathrm{Cu}(\mathrm{II})$ and the metal is displaced from the iminocoumarin. With the destabilization from removal of metal coordination, the imine is then hydrolyzed to give a highly fluorescent aldehyde derivative and result in a fluorescence turn-on. Treatment of the $\mathrm{Cu}$ (II) complex ensemble with other biological thiols such as Hcy and GSH, but not other amino acids including His, can also result in a fluorescence enhancement. The iminocoumarin-Cu(II) ensemble has also been applied in the intracellular Cys imaging in HepG2 cells stimulated by selective thiol modifying agent $N$-ethylmaleimide. A few other Cys probes featuring the same $\mathrm{Cu}(\mathrm{II})$ displacement followed by imine hydrolysis with other fluorophores have also been reported $[75,76]$.

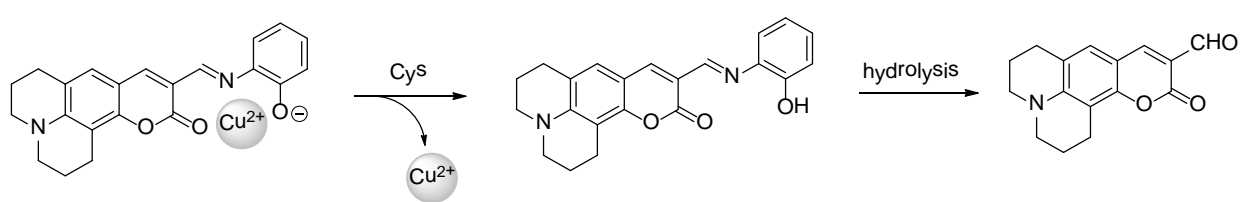

Figure 10. A fluorescent Cys probe based on copper(II) displacement and hydrolysis [74].

In the above examples, both the detection mechanisms for His and Cys involve $\mathrm{Cu}$ (II) coordination and/or displacement. In most of the cases, Cys displaces $\mathrm{Cu}(\mathrm{II})$ from the probes to restore the quenched fluorescence, whereas His acts as an additional ligand to form a ternary complex or displace $\mathrm{Cu}$ (II) to change the photophysical properties of the probes. Of note, the Cu-Cys (or Cu-His) complexes from the demetallation of the probes were usually not well characterized. Whether the copper displacement by Cys involves a reduction from $\mathrm{Cu}(\mathrm{II})$ to $\mathrm{Cu}(\mathrm{I})$, which might be a mechanism that provides the observed selectivity, was not 
studied. Nevertheless, since the detection of both amino acids involve $\mathrm{Cu}$ (II) coordination, it is perhaps not surprising to notice that some of these probes could be interfered by each other, and their differentiation will therefore require a highly sophisticated mechanism to distinguish the subtle differences in $\mathrm{Cu}$ (II) coordination by the two amino acids.

\section{Luminescent Probes for Small Reactive Species}

Reactive species such as reactive oxygen species (ROS, e.g. $\mathrm{H}_{2} \mathrm{O}_{2}, \mathrm{O}_{2}{ }^{-}$and ${ }^{\circ} \mathrm{OH}$ ) $[77,78]$ and reactive nitrogen species (RNS, e.g. $\mathrm{NO}$ and $\left.\mathrm{ONOO}^{-}\right)[79,80]$ are highly reactive, shortlived chemical species that play important roles in both normal physiology and disease pathology. The chemistry and biology of small reactive species in signaling and stress response have been an intense research topic, and bioanalytical tools that are able to selectively capture, recognize and report the level of the short-lived reactive species in the complex biological milieu are highly sought after. In recent years, different strategies spanning across many areas in synthetic chemistry and biology have been exploited in the development of luminescent probes for the selective detection of ROS and RNS in cells, tissues and small animals [81, 82]. Indeed, the many possibilities in the coordination and chemical reactivity of various metals with different molecules/substrates offer a highly versatile platform for developing bioanalytical tools to interrogate the roles of these reactive species in biological samples. Here we will discuss examples of the use of copper coordination chemistry in the development of luminescent probes for these reactive species.

Nitric oxide probes. In addition to being a well-known gaseous neurotransmitter, nitric oxide radical (NO) is also responsible for other important physiological responses such as vasodilation and immune response [83, 84]. Moreover, reaction of NO with superoxide $\left(\mathrm{O}_{2}{ }^{-}\right)$ produces peroxynitrite $\left(\mathrm{ONOO}^{-}\right)$which is an RNS that contributes to intracellular nitrosative stress [85]. As a strong m-acceptor, NO forms stable complexes with transition metals with a strong back $\pi$ bonding. The radical can also be readily oxidized by dioxygen or transition metal ions [86, 87]. In fact, fluorescent probes that can directly detect NO but not its oxidized products are largely metal-based using various transition metals such as iron [88], cobalt [89-91], copper [92, 93], ruthenium [94] and rhodium [95]. We will discuss here examples of selective NO probes based on copper chemistry.

Ford and co-workers have reported a $\mathrm{Cu}$ (II) complex of an anthracene-appended cyclam derivative that showed a fluorescence response to NO (Figure 11a) [96]. The anthracene units in the square planar $\mathrm{Cu}(\mathrm{II})$ complex are non-emissive due to intramolecular quenching by the paramagnetic $\mathrm{d}^{9} \mathrm{Cu}(\mathrm{II})$, but becomes luminescent upon reaction with NO. Combined NMR, MS, UV-Vis and electrochemical studies revealed that the restored fluorescence is a result of $N$-nitrosation of the cyclam, reduction of the paramagnetic $d^{9} \mathrm{Cu}$ (II) to the diamagnetic $\mathrm{d}^{10} \mathrm{Cu}(\mathrm{I})$, and copper displacement from the $N$-nitrosated cyclam. Lippard and co-workers have reported a $\underline{\mathbf{C u}}$ (II) fluorescein-based ligand complex, CuFL, derived from quinolinylamino phenolate, as an NO-selective fluorescent probe (Figure 11b) [97]. CuFL showed an 11-fold fluorescence enhancement that is selective to NO over other reactive species such as $\mathrm{HNO}, \mathrm{NO}_{2}^{-}, \mathrm{NO}_{3}^{-}, \mathrm{ONOO}^{-}, \mathrm{H}_{2} \mathrm{O}_{2}, \mathrm{O}_{2}^{-}$and $\mathrm{ClO}^{-}$. The $\mathrm{NO}$ induced fluorescence turn-on was found to be also due to the reduction of $\mathrm{Cu}(\mathrm{II})$ to $\mathrm{Cu}(\mathrm{I})$, ligand $\mathrm{N}$ nitrosation and copper decomplexation [98]. CuFL has been employed in the cellular imaging of intracellular NO production in murine macrophage RAW 264.7 and human 
neuroblastoma SK-N-SH cells that were stimulated by lipopolysaccharides, interferon IFN- $\gamma$ or estrogen treatment [98]. Other examples of NO fluorescent probes featuring the same reduction- $N$-nitrosation-decomplexation mechanism with longer emission wavelengths (Figures 11c and 11d) [99, 100], cellular trappability (Figures 11e and 11f) [101, 102], and other photophysical and cellular properties have also been reported [103-108]. Of note, selectivity of these $\mathrm{Cu}(\mathrm{II})$-based $\mathrm{NO}$ probes were usually studied against selected ROS and RNS, but not other biologically competitive $\mathrm{Cu}(\mathrm{II})$ ligands (e.g. $\mathrm{GSH}, \mathrm{H}_{2} \mathrm{~S}, \mathrm{Cys}$ and His) which may also displace the $\mathrm{Cu}(\mathrm{II})$ from the probes and result in a fluorescence turn-on. Some of these probes have also not been tested against HNO (Figures 11a and 11d).
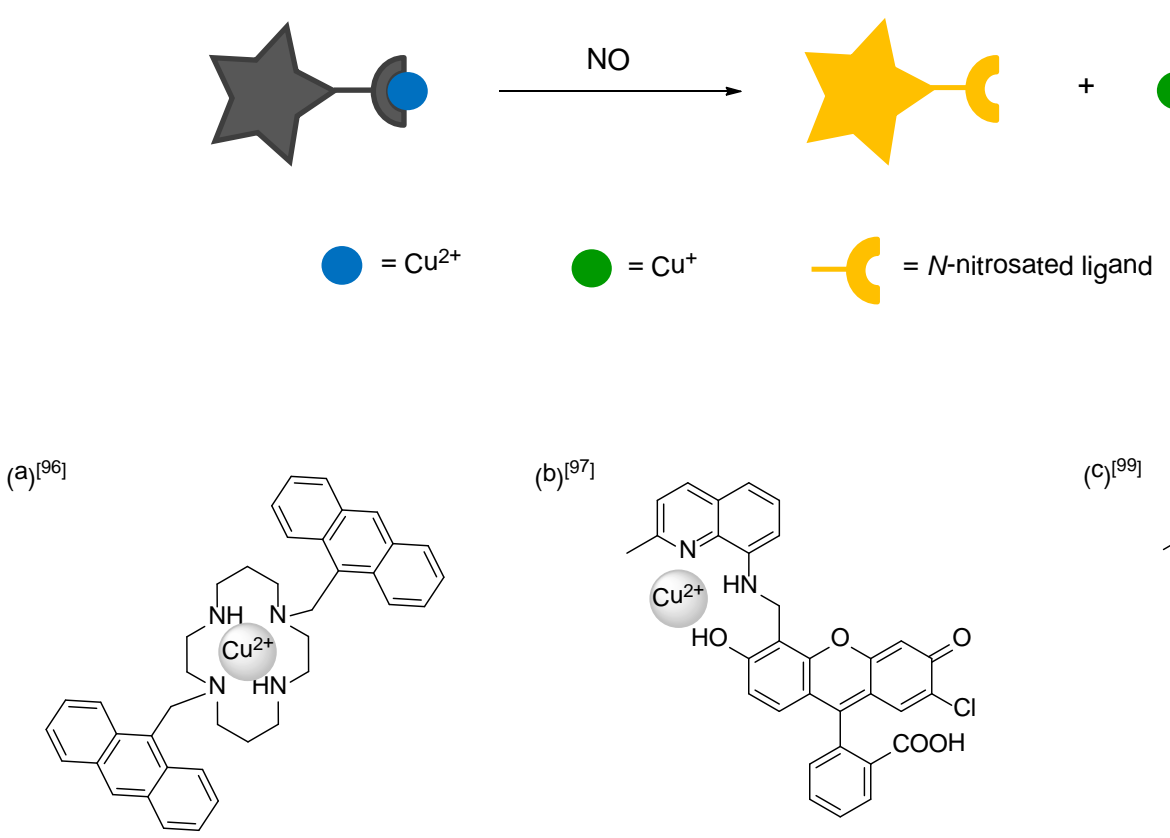

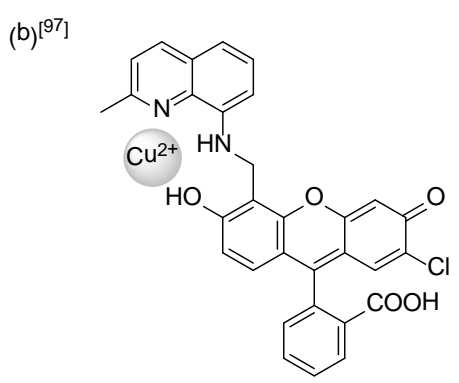

CuFL

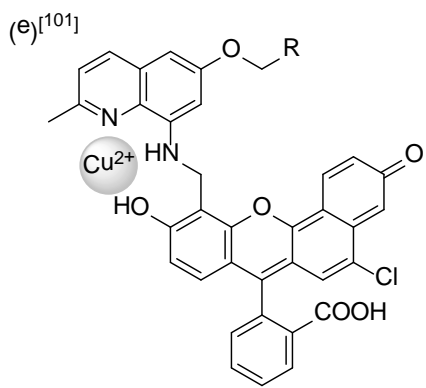

$\mathrm{R}=\mathrm{cOOEt}, \mathrm{CONH}_{\text {(dextran) }}$

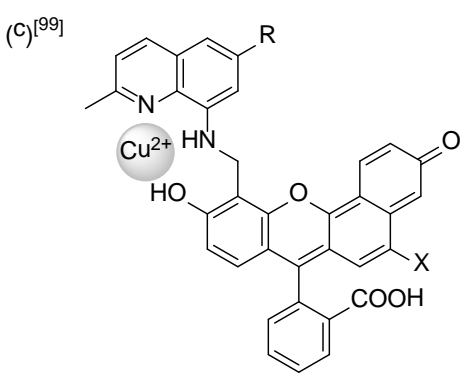

$\mathrm{X}=\mathrm{H}, \mathrm{Br}$

$\mathrm{R}=\mathrm{H}, \mathrm{OCH}_{2} \mathrm{CO}_{2} \mathrm{Et}$

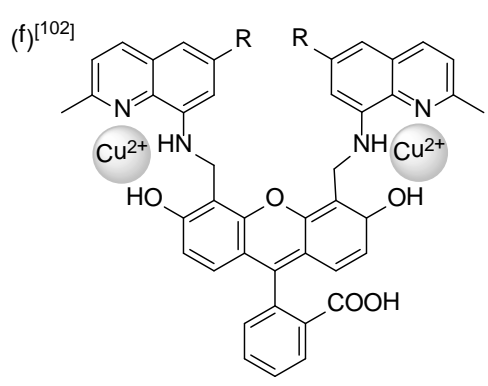

$\mathrm{R}=\mathrm{H}, \mathrm{OCH}_{2} \mathrm{COOH}, \mathrm{OCH}_{2} \mathrm{COOEt}$

Figure 11. Examples of fluorescent $\mathrm{NO}$ probes with a $\mathrm{Cu}(\mathrm{II})$ reduction and ligand $\mathrm{N}$ nitrosation mechanism for fluorescence turn-on response.

In addition to the copper reduction-ligand $N$-nitrosation-copper displacement mechanism, some other $\mathrm{Cu}$ (II)-based NO selective fluorescent probes may involve only $\mathrm{Cu}$ (II) reduction and/or metal displacement. For example, Lippard and co-workers have reported the $\mathrm{Cu}$ (II) 
complexes of dansyl-functionalized sulfonamide ligands for NO sensing in pure aqueous solutions (Figure 12a) [109]. Turn-on of the dansyl fluorescence was suggested to be due to the reduction of $\mathrm{Cu}(\mathrm{II})$ to $\mathrm{Cu}(\mathrm{I})$ and the protonation of the sulfonamide ligands. The NOdependent fluorescence enhancement of a similar $\mathrm{Cu}$ (II) complex of a dansyl-functionalized ligand with a pyrazole donor, on the other hand, was shown to be due only to the reduction of $\mathrm{Cu}(\mathrm{II})$ to $\mathrm{Cu}(\mathrm{I})$ with no ligand $N$-nitrosation or metal displacement (Figure 12b) [110]. Costero and co-workers have reported more recently a bipyridine-functionalized BODIPY $\mathrm{Cu}$ (II) complex which showed fluorescence turn-on to NO in live cells that involves only $\mathrm{Cu}(\mathrm{II})$ reduction (Figure 12c) [111].
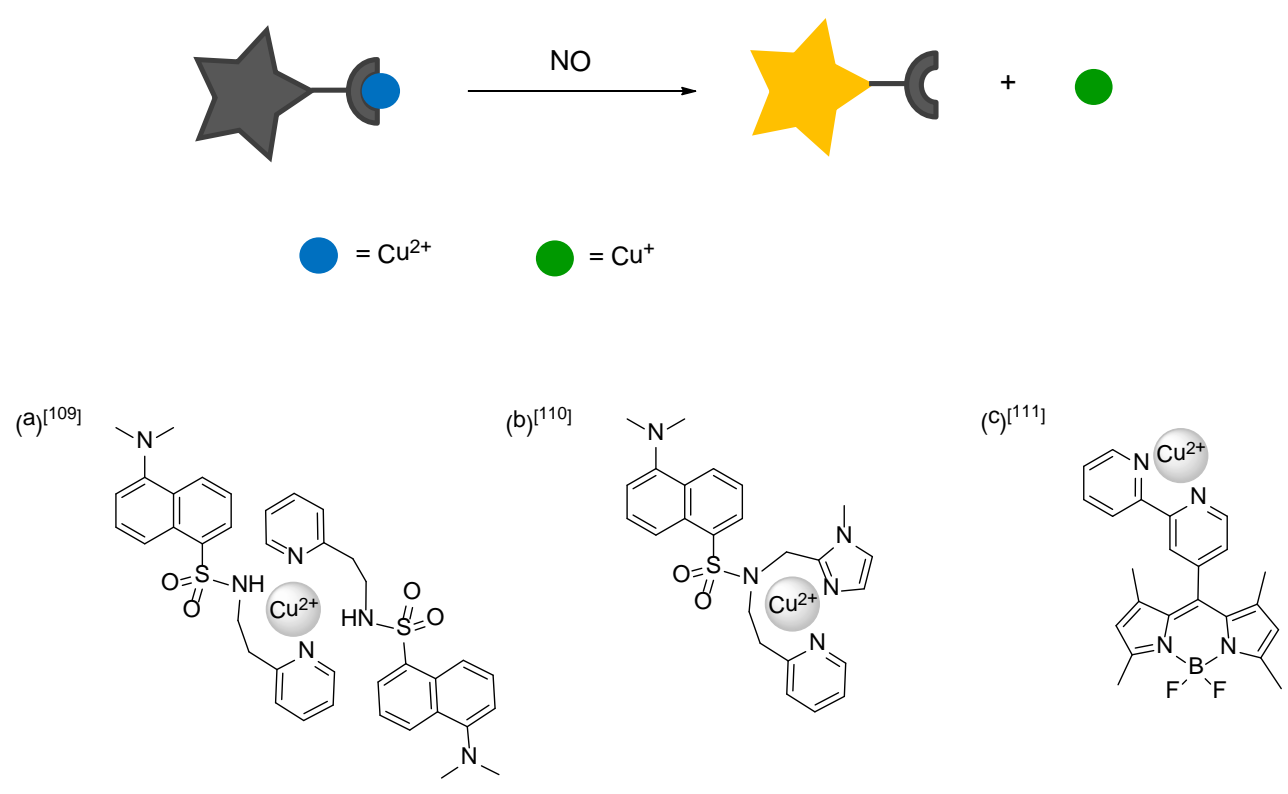

Figure 12. Examples of fluorescence turn-on NO probes with a $\mathrm{Cu}(\mathrm{II})$ reduction mechanism.

Nitroxyl probes. Nitroxyl (HNO) is the one-electron reduced, protonated form of NO. Both NO and $\mathrm{HNO}$ can be easily oxidized. Being in different oxidation states, $\mathrm{NO}$ and HNO have distinct chemistry and biological effects $[112,113]$. In some examples of copper-based NO fluorescent probes, $\mathrm{Cu}(\mathrm{II})$ reduction to $\mathrm{Cu}(\mathrm{I})$ may not be exclusive to NO but can also occur with other chemically similar reducing agents such as HNO [114, 115]. For example, the three $\mathrm{Cu}$ (II) complexes of the benzoresorufin-based quinolinylamino ligand were found to give fluorescence turn-on response for both NO and HNO (Figures 13a and 13b) [116]. $\mathrm{Cu}$ (II) reduction and ligand $\mathrm{N}$-nitrosation was found to be responsible for the NO-dependent fluorescence enhancement, similar to those NO probes discussed above. On the other hand, electrochemical studies revealed that oxidation of $\mathrm{HNO}$ to $\mathrm{NO}$ by the $\mathrm{Cu}(\mathrm{II})$ complexes is thermodynamically feasible, with quasi-reversible reduction of the copper(II) complexes occurring at $10-150 \mathrm{mV}$ vs $\mathrm{Fc} / \mathrm{Fc}^{+}$(ferrocene/ferrocenium) in acetonitrile, and that $\mathrm{NO}$ was found irreversibly reduced at $-1 \mathrm{~V}$ vs $\mathrm{Fc} / \mathrm{Fc}^{+}$under similar conditions. The formation of $\mathrm{NO}$ gas upon reaction of the $\mathrm{Cu}$ (II) complexes with $\mathrm{HNO}$ has also been confirmed by mass spectrometry, thus explaining the HNO-induced fluorescence enhancement is also due to the same copper(II) reduction-ligand $N$-nitrosation mechanism [117]. A similar 
napthaleneimide-based $\mathrm{Cu}(\mathrm{II})$ complex also showed dual $\mathrm{NO}$ and $\mathrm{HNO}$ induced fluorescence enhancement in aqueous buffer and living cells (Figure 13c) [117].
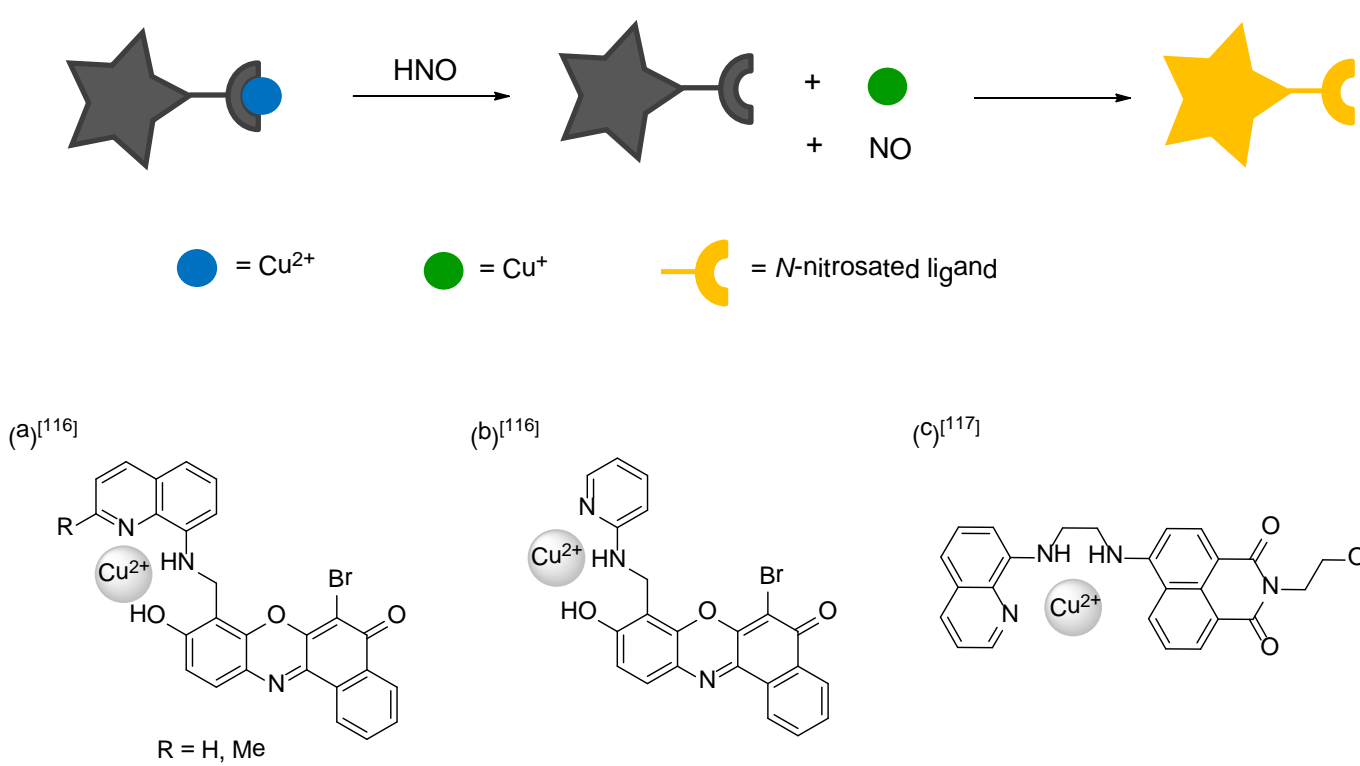

$$
\left({ }^{(}\right)^{[117]}
$$

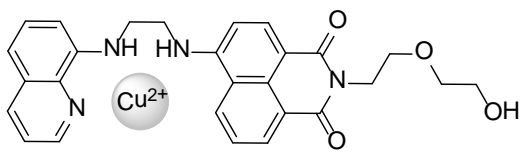

Figure 13. Examples of fluorescent NO probes that are also responsive to HNO.

Despite not being exclusively selective, the dual responsiveness of these fluorescent probes to $\mathrm{NO}$ and $\mathrm{HNO}$ suggests that, by proper tuning of the reduction potential of the $\mathrm{Cu}$ (II) complexes, attaining HNO selectivity is possible. Indeed, by using the tripodal triazolyl(dipicolyl)amine ligand, Lippard and Yao have respectively reported $\underline{\mathbf{C u}}$ (II) complexes of BODIPY-triazole (CuBOT-1) (Figure 14a) [118] and coumarin-triazole (CuCOT-1) (Figure 14b) [119] as HNO-selective probes for HNO imaging in living cells. Both CUBOT-1 and CuCOT-1 display good selectivity to HNO over NO and other RNS including $\mathrm{NO}_{3}{ }^{-}, \mathrm{NO}_{2}{ }^{-}, \mathrm{ONOO}^{-}$and $\mathrm{S}$-nitrosocysteine, and detect intracellular $\mathrm{HNO}$ in $\mathrm{HeLa}$ or A375 (human malignant melanoma) cells stimulated by Angeli's salt $\left(\mathrm{Na}_{2} \mathrm{~N}_{2} \mathrm{O}_{3}\right)$. The mechanism of HNO detection and selectivity over NO by CUBOT-1 has been studied by electrochemistry and computation [120]. From the cyclic voltammetry experiments, it was found that the reduction of $\mathrm{Cu}(\mathrm{II})$ to $\mathrm{Cu}(\mathrm{I})$ in CuBOT-1 in PBS buffer at $\mathrm{pH} 7.4$ by $\mathrm{HNO}$ is thermodynamically feasible, and results from the computational studies are suggestive of a proton-coupled electron transfer mechanism in the oxidation of HNO to NO, with the $\mathrm{Cu}(\mathrm{II})$ and triazole in CUBOT-1 acting respectively as the electron and proton acceptor. On the other hand, electrochemical studies showed that NO oxidation by CUBOT-1 is thermodynamically uphill, which explains the observed HNO selectivity over NO. A major limitation of these $\mathrm{HNO}$ probes is the competitive reduction by other biological reducing agents, and indeed CuBOT-1 and CuCOT-1 do show fluorescence enhancement in the presence of cysteine and/or ascorbate. Attention will be required when these probes are to be applied in cells. More recently, other ligand systems which provide a suitable reduction potential and thus HNO selectivity have also been reported [121-123]. For example, using a cyclam-based ligand to tune the reaction kinetics at the $\mathrm{Cu}(\mathrm{II})$ centre, HNO probes that are 
selective against NO, RNS, ascorbate and biological thiols (e.g. Cys and GSH) have been reported (Figures 14d [122] and 14e [123]).

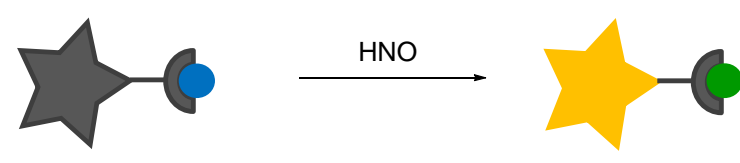

$O=\mathrm{Cu}^{2+} \quad \mathrm{O} \mathrm{Cu}^{+}$
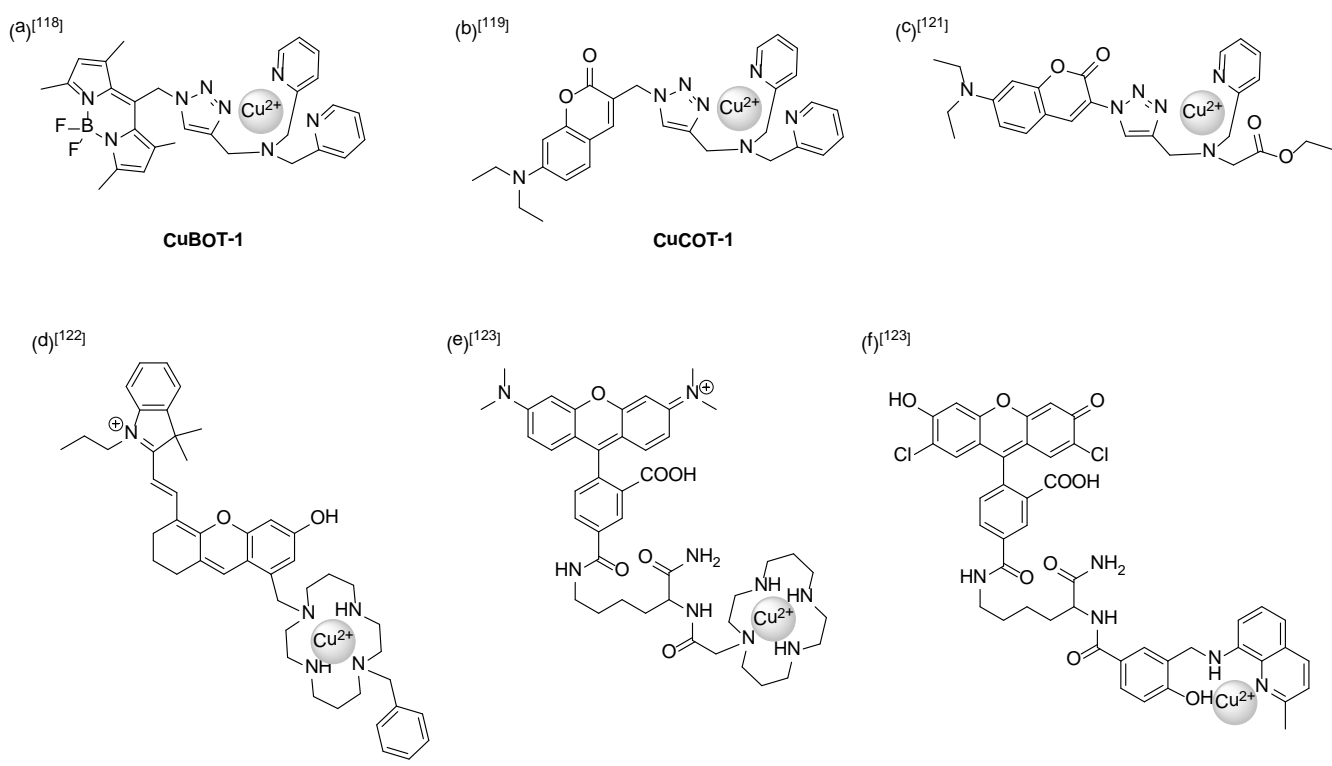

Figure 14. Examples of fluorescent HNO probes.

Hydrogen sulfide probes. Hydrogen sulfide $\left(\mathrm{H}_{2} \mathrm{~S}\right)$ is another endogenous gaseous molecule that is involved in biological signaling [124]. By combining the fluorescence quenching effect of the $d^{9}$ paramagnetic $\mathrm{Cu}(\mathrm{II})$ and the high stability of copper(II) sulfide (CuS, $\mathrm{K}_{\mathrm{sp}} \approx 10^{-36}$ ), $\mathrm{H}_{2} \mathrm{~S}$ fluorescence turn-on driven by CuS formation and precipitation has been a major strategy for the design of $\mathrm{H}_{2} \mathrm{~S}$-selective fluorescent probes [125-127].

One early example that exploits copper(II) sulfide precipitation in $\mathrm{H}_{2} \mathrm{~S}$ fluorescence sensing is given by Chang and co-workers. A Cu(II) complex of a dipicolylamine-appended fluorescein derivative was prepared as a $\mathrm{H}_{2} \mathrm{~S}$ probe (Figure 15a) [128]. The fluorescence of the ligand-fluorophore conjugate was initially quenched by the paramagnetic $d^{9} \mathrm{Cu}(\mathrm{II})$, but a robust fluorescence turn-on was observed upon reaction with sufide ions. Formation of CuS precipitates upon reaction of the probe with sulfide has been confirmed by energy-dispersive $\mathrm{X}$-ray measurement. The probe is not responsive towards other inorganic anions (e.g. halides, sulfates, nitrates and cyanide) and no fluorescence enhancement was observed. However, the selectivity has not been tested against other biological thiols such as GSH, which can be present in millimolar range in cells and may also interfere with the $\mathrm{H}_{2} \mathrm{~S}$ detection through a competitive binding to the $\mathrm{Cu}(\mathrm{II})$ of the probe. To overcome the possible 
interference by intracellular thiols, Nagano and co-worker have reported hydrogen sulfide imaging probe, HSip-1, featuring a cyclen ligand coordinated to a $\mathrm{Cu}(\mathrm{II})$ ion as a selective $\mathrm{H}_{2} \mathrm{~S}$ probe (Figure 10b) [129]. The use of cyclen was to enhance the stability of the $\mathrm{Cu}(\mathrm{II})$ complex so as to provide a better selectivity to $\mathrm{H}_{2} \mathrm{~S}$ over $\mathrm{GSH}$. It was found that the use of other azamacrocycles such as TACN (1,4,7-triazacyclononane) and cyclam as the ligand will result in a reduced $\mathrm{H}_{2} \mathrm{~S}$ sensitivity and/or selectivity, probably because of the subtle differences in the stability of the $\mathrm{Cu}(\mathrm{II})$ complexes with slightly different azamacrocyclic ligands [129]. HSip-1 shows fluorescence turn-on only to $\mathrm{H}_{2} \mathrm{~S}$ but not biological thiols such as Cys, Hcy and GSH, and is also selective against other inorganic sulfur compounds, ROS and RNS. HSip-1 has been used to detect enzymatically produced $\mathrm{H}_{2} \mathrm{~S}$ in buffer and cell lysate, and image intracellular $\mathrm{H}_{2} \mathrm{~S}$ in live HeLa cells [130-132].

A few others $\mathrm{H}_{2} \mathrm{~S}$ probes based on the same CuS precipitation mechanism with different ligands and/or fluorophores of different emission colors have also been reported [133-135]. However, selectivity of these probes has been tested only against inorganic anions such as phosphates, carbonates and cyanide. Fluorescence response of these probes towards biological thiols (e.g. Cys and GSH) and biological reductants (e.g. NO, HNO and ascorbate), which could also respectively displace or reduce the $\mathrm{Cu}(\mathrm{II})$ quencher, has not been studied. One important issue in $\mathrm{H}_{2} \mathrm{~S}$ sensing using the CuS precipitation strategy is that the mechanism for the fluorescence response is not exclusive to the reaction between $\mathrm{H}_{2} \mathrm{~S}$ and $\mathrm{Cu}(\mathrm{II})$. Other reactions of the $\mathrm{Cu}(\mathrm{II})$ in the probes with other biological species, such as metal displacement by His and Cys or $\mathrm{Cu}(\mathrm{II})$ reduction by $\mathrm{NO}$ and $\mathrm{HNO}$ as discussed above, may lead to other competitive pathways that also remove the paramagnetic $\mathrm{Cu}$ (II) quencher and result in a fluorescence response. More selective and specific chemistry that can distinguish $\mathrm{H}_{2} \mathrm{~S}$ from these chemically similar species will be required if probes of high selectivity are needed. For example, one other common strategy for developing selective $\mathrm{H}_{2} \mathrm{~S}$ probes involves the selective reduction of organic arylazide by $\mathrm{H}_{2} \mathrm{~S}$ [136]. 

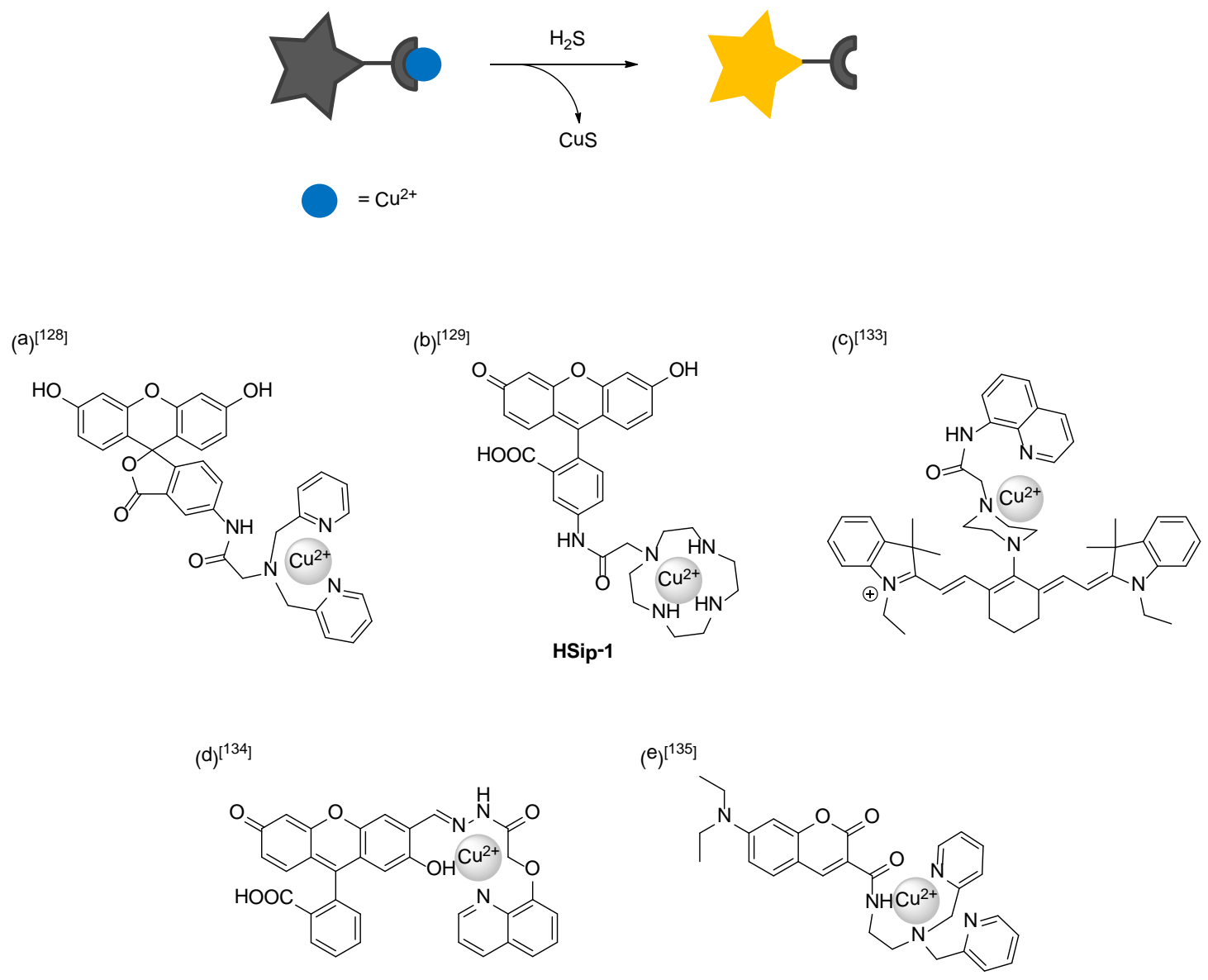

Figure 15. Examples of fluorescent $\mathrm{H}_{2} \mathrm{~S}$ probes based on a CuS precipitation mechanism.

\section{Concluding Remarks}

The diverse chemistry of copper has provided the element a central and unique importance in natural biological systems. Different chemical reactions mediated by copper have also been exploited in the development of analyte-selective luminescent probes for the interrogation of the roles and functions of specific ions and molecules in biological systems. In particular, fluorescent probes that are responsive towards labile copper, His, Cys, NO, $\mathrm{HNO}$ and $\mathrm{H}_{2} \mathrm{~S}$ have been successfully developed based on $\mathrm{Cu}(\mathrm{I})$-thiol coordination, $\mathrm{Cu}(\mathrm{II})$ displacement, $\mathrm{Cu}(\mathrm{II})$-catalyzed hydrolysis, $\mathrm{Cu}(\mathrm{II})$-mediated oxidation, $\mathrm{Cu}(\mathrm{I})-\mathrm{O}_{2}$ chemistry, $\mathrm{Cu}$ (II) reduction, CuS precipitation and other copper-based reactions. In addition to diversifying the present probes with various cellular and photophysical properties to fit the needs of different experiments and expanding the scope of bioanalytes that can be detected, another important direction for future development will be further improving the selectivity of the probes and more careful verifications of the in vitro selectivity in relevant biological conditions, especially when the chemistry involved in the probes could be applied to other chemically and/or biologically similar species (e.g. Cu(II) coordination by His and Cys, $\mathrm{Cu}$ (II) reduction by $\mathrm{NO}$ and $\mathrm{HNO}$ ). With creative and careful molecular designs, the rich chemistry of copper (and other metals) can be turned into useful molecular tools for studying the complex interplays of biological species in the dynamic biological environment. 
Abbreviations

Ala: alanine

Asp: aspartate

Atox 1: Antioxidant protein 1

BINOL: 1,1'-bi-2-naphthol

BODIPY: boron dipyrromethene

CCL: copper caged luciferin

CuBOT: Cu(II) BODIPY-triazole

CuCOT: $\mathrm{Cu}(\mathrm{II})$ coumarin-triazole

CuFL: Cu(II) fluorescein-based ligand

CS: copper sensor

cyclam: 1,4,8,11-tetraazacyclotetradecane

cyclen: 1,4,7,10-tetraazacyclododecane

Cys: cysteine

CTAP: copper-responsive triarylpyrozoline

$\mathrm{Fc} / \mathrm{Fc}^{+}$: ferrocene/ferrocenium

FluTPA: fluorescein tris(2-picolylamine)

Glu: glutamate

GSH: glutathione

Hcy: homocysteine

His: histidine

HPLC: high performance liquid chromatography

HSip-1: hydrogen sulfide imaging probe-1

IR: infrared

Met: methionine

Mito-CS1: mitochondria-targeting copper sensor

NMR: nuclear magnetic resonance 
PBS: phosphate-buffered saline

RCS1: ratiometric copper sensor

RNS: reactive nitrogen species

ROS: reactive oxygen species

Ser: serine

SCO1/SCO2: Synthesis of cytochrome c oxidase

TACN: 1,4,7-triazacyclononane

TPA: tris(2-picolyl)amine

Tpy: 2,6-terpyridine

Tyr: tyrosine

UV-Vis: ultraviolet-visible

\section{Acknowledgements}

We thank the supports from the Croucher Foundation, the Research Grants Council of the Hong Kong Special Administrative Region, China (HKU 17300315), and the University of Hong Kong.

\section{References}

[1] R. Uauy, M. Olivares, M. Gonzalez, Am. J. Clin. Nutr. 67 (1998) 952S-959S.

[2] D.J. Waggoner, T.B. Bartnikas, J.D. Gitlin, Neurobiol. Dis. 6 (1999) 221-230.

[3] J. Chan, S.C. Dodani, C.J. Chang, Nat. Chem. 4 (2012) 973-984.

[4] E.L. Que, D.W. Domaille, C.J. Chang, Chem. Rev. 108 (2008) 1517-1549.

[5] D.W. Domaille, E.L. Que, C.J. Chang, Nat. Chem. Biol. 4 (2008) 168-175.

[6] T. Ueno, T. Nagano, Nature methods 8 (2011) 642.

[7] K.M. Ramos-Torres, S. Kolemen, C.J. Chang, Isr. J. Chem. 56 (2016) 724-737.

[8] Y.H. Hung, A.I. Bush, R.A. Cherny, J. Biol. Inorg. Chem. 15 (2010) 61-76.

[9] M.L. Schlief, J.D. Gitlin, Mol. Neurobiol. 33 (2006) 81-90.

[10] C. dos Santos Carvalho, M.N. Fernandes, Comp. Biochem. Physiol., Part A Mol. Integr. Physiol. 151 (2008) 437-442.

[11] J. Suliburska, P. Bogdański, D. Pupek-Musialik, Z. Krejpcio, Biol. Trace Elem. Res. 139 (2011) 137-150. 
[12] L. Krishnamoorthy, J.A. Cotruvo Jr, J. Chan, H. Kaluarachchi, A. Muchenditsi, V.S. Pendyala, S. Jia, A.T. Aron, C.M. Ackerman, M.N. Vander Wal, Nat. Chem. Biol. 12 (2016) 586-592.

[13] C.J. Fahrni, Curr. Opin. Chem. Biol. 17 (2013) 656-662.

[14] J.A. Cotruvo Jr, A.T. Aron, K.M. Ramos-Torres, C.J. Chang, Chem. Soc. Rev. 44 (2015) $4400-4414$

[15] C.J. Lin, H.C. Huang, Z.F. Jiang, Brain Res. Bull 82 (2010) 235-242.

[16] M. Lovell, J. Robertson, W. Teesdale, J. Campbell, W. Markesbery, J. Neurol. Sci. 158 (1998) 47-52.

[17] L. Yang, R. McRae, M.M. Henary, R. Patel, B. Lai, S. Vogt, C.J. Fahrni, Proc. Natl. Acad. Sci. U.S.A. 102 (2005) 11179-11184.

[18] M.T. Morgan, P. Bagchi, C.J. Fahrni, J. Am. Chem. Soc. 133 (2011) 15906-15909.

[19] L. Zeng, E.W. Miller, A. Pralle, E.Y. Isacoff, C.J. Chang, J. Am. Chem. Soc. 128 (2006) $10-11$.

[20] S.C. Dodani, D.W. Domaille, C.I. Nam, E.W. Miller, L.A. Finney, S. Vogt, C.J. Chang, Proc. Natl. Acad. Sci. USA. 108 (2011) 5980-5985.

[21] D.W. Domaille, L. Zeng, C.J. Chang, J. Am. Chem. Soc. 132 (2010) 1194-1195.

[22] C. Satriano, G.T. Sfrazzetto, M.E. Amato, F.P. Ballistreri, A. Copani, M.L. Giuffrida, G. Grasso, A. Pappalardo, E. Rizzarelli, G.A. Tomaselli, Chem. Commun. 49 (2013) 55655567.

[23] S.C. Dodani, S.C. Leary, P.A. Cobine, D.R. Winge, C.J. Chang, J. Am. Chem. Soc. 133 (2011) 8606-8616.

[24] X. Cao, W. Lin, W. Wan, Chem. Commun. 48 (2012) 6247-6249.

[25] S.C. Dodani, A. Firl, J. Chan, C.I. Nam, A.T. Aron, C.S. Onak, K.M. Ramos-Torres, J. Paek, C.M. Webster, M.B. Feller, Proc. Natl. Acad. Sci. USA 111 (2014) 16280-16285.

[26] T. Hirayama, G.C. Van de Bittner, L.W. Gray, S. Lutsenko, C.J. Chang, Proc. Natl. Acad. Sci. USA 109 (2012) 2228-2233.

[27] C.S. Lim, J.H. Han, C.W. Kim, M.Y. Kang, D.W. Kang, B.R. Cho, Chem. Commun. 47 (2011) 7146-7148.

[28] M.L. Giuffrida, E. Rizzarelli, G.A. Tomaselli, C. Satriano, G.T. Sfrazzetto, Chem. Commun. 50 (2014) 9835-9838.

[29] C. Shen, J.L. Kolanowski, C.M.N. Tran, A. Kaur, M.C. Akerfeldt, M.S. Rahme, T.W. Hambley, E.J. New, Metallomics 8 (2016) 915-919.

[30] L. Banci, I. Bertini, S. Ciofi-Baffoni, T. Kozyreva, K. Zovo, P. Palumaa, Nature 465 (2010) 645-648. 
[31] R.F. Viguier, A.N. Hulme, J. Am. Chem. Soc. 128 (2006) 11370-11371.

[32] M. Taki, S. Iyoshi, A. Ojida, I. Hamachi, Y. Yamamoto, J. Am. Chem. Soc. 132 (2010) 5938-5939.

[33] M. Taki, K. Akaoka, K. Mitsui, Y. Yamamoto, Org. Biomol. Chem. 12 (2014) 4999-5005.

[34] M.C. Heffern, H.M. Park, H.Y. Au-Yeung, G.C. Van de Bittner, C.M. Ackerman, A. Stahl, C.J. Chang, Proc. Natl. Acad. Sci. USA 113 (2016) 14219-14224.

[35] H.Y. Au-Yeung, E.J. New, C.J. Chang, Chem. Commun. 48 (2012) 5268-5270.

[36] H.Y. Au-Yeung, J. Chan, T. Chantarojsiri, C.J. Chang, J. Am. Chem. Soc. 135 (2013) 15165-15173.

[37] P.S. Nayab, M. Shkir, Sens. Actuator B-Chem. 245 (2017) 395-405.

[38] H.N. Kim, M.H. Lee, H.J. Kim, J.S. Kim, J. Yoon, Chem. Soc. Rev. 37 (2008) 14651472.

[39] J. Kovács, A. Mokhir, Inorg. Chem. 47 (2008) 1880-1882.

[40] J. Wang, Q. Zong, Sens. Actuator B-Chem. 216 (2015) 572-577.

[41] N. Li, Y. Xiang, A. Tong, Chem. Commun. 46 (2010) 3363-3365.

[42] V. Dujols, F. Ford, A.W. Czarnik, J. Am. Chem. Soc. 119 (1997) 7386-7387.

[43] L. Yuan, W. Lin, B. Chen, Y. Xie, Org. Lett. 14 (2011) 432-435.

[44] M.M. Yu, Z.X. Li, L.H. Wei, D.H. Wei, M.S. Tang, Org. Lett. 10 (2008) 5115-5118.

[45] S. KyungáKwon, H. NaáLee, Chem. Commun. 45 (2008) 5915-5917.

[46] H. Li, P. Zhang, L.P. Smaga, R.A. Hoffman, J. Chan, J. Am. Chem. Soc. 137 (2015) 15628-15631.

[47] D. Wang, Y. Shiraishi, T. Hirai, Chem. Commun. 47 (2011) 2673-2675.

[48] W. Lin, L. Long, B. Chen, W. Tan, W. Gao, Chem. Commun. 46 (2010) 1311-1313.

[49] Z. Shi, X. Tang, X. Zhou, J. Cheng, Q. Han, J.A. Zhou, B. Wang, Y. Yang, W. Liu, D. Bai, Inorg. Chem. 52 (2013) 12668-12673.

[50] Y. Zhou, J. Yoon, Chem. Soc. Rev. 41 (2012) 52-67.

[51] R.S. Bhosale, G.V. Shitre, R. Kumar, D.O. Biradar, S.V. Bhosale, R. Narayan, S.V. Bhosale, Sens. Actuator B-Chem. 241 (2017) 1270-1275.

[52] H. Refsum, P.M. Ueland, O. Nygård, S.E. Vollset, Annu. Rev. Med. 49 (1998) 31-62.

[53] L. Helm, A.E. Merbach, Chem. Rev. 105 (2005) 1923-1959.

[54] J. De Silva, R. Williams, The biological chemistry of the elements, Inorganic Chemistry of Life, Clarendon Press, Oxford, NY (1991) 541. 
[55] J. Wang, H.B. Liu, Z. Tong, C.S. Ha, Coord. Chem. Rev. 303 (2015) 139-184.

[56] S. Zhang, C. Yang, W. Zhu, B. Zeng, Y. Yang, Y. Xu, X. Qian, Org. Biomol. Chem. 10 (2012) 1653-1658.

[57] T. Chen, L. Yin, C. Huang, Y. Qin, W. Zhu, Y. Xu, X. Qian, Biosens. Bioelectron. 66 (2015) 259-265.

[58] H.I. Un, S. Wu, C.B. Huang, Z. Xu, L. Xu, Chem. Commun. 51 (2015) 3143-3146.

[59] X. Wang, Q. Miao, T. Song, Q. Yuan, J. Gao, G. Liang, Analyst 139 (2014) 3360-3364.

[60] A. Meister, J Biol Chem. 263, 1988, 17205-17208.

[61] Z. Huang, J. Du, J. Zhang, X.Q. Yu, L. Pu, Chem. Commun. 48 (2012) 3412-3414.

[62] X. Chen, Y. Zhou, X. Peng, J. Yoon, Chem. Soc. Rev. 39 (2010) 2120-2135.

[63] H.S. Jung, X. Chen, J.S. Kim, J. Yoon, Chem. Soc. Rev. 42 (2013) 6019-6031.

[64] M. Prudent, H.H. Girault, Metallomics 1 (2009) 157-165.

[65] A.V. Kachur, C.J. Koch, J.E. Biaglow, Free Radical Res. 31 (1999) 23-34.

[66] R. Peng, L. Lin, X. Wu, X. Liu, X. Feng, J. Org. Chem. 78 (2013) 11602-11605.

[67] Q. Li, Y. Guo, S. Shao, Sens. Actuator B-Chem. 171 (2012) 872-877.

[68] T. Anand, G. Sivaraman, D. Chellappa, J. Photochem. Photobiol. A-Chem. 281 (2014) 47-52.

[69] G. He, J. Li, L. Yang, C. Hou, T. Ni, Z. Yang, X. Qian, C. Li, PloS One 11 (2016) e0148026.

[70] Y.G. Shi, J.H. Yao, Y.L. Duan, Q.L. Mi, J.H. Chen, Q.Q. Xu, G.Z. Gou, Y. Zhou, J.F. Zhang, Bioorg. Med. Chem. Lett. 23 (2013) 2538-2542.

[71] M.M. Ramasamy, M. Duraiyarasu, N. Thavasilingam, M. Paramasivam, A. Balasubramaniem, M. Kumar, Eur. J. Inorg. Chem. (2016) 1007-1016.

[72] Q.H. You, A.W.M. Lee, W.H. Chan, X.M. Zhu, K.C.F. Leung, Chem. Commun. 50 (2014) 6207-6210.

[73] H. Agarwalla, N. Taye, S. Ghorai, S. Chattopadhyay, A. Das, Chem. Commun. 50 (2014) 9899-9902.

[74] H.S. Jung, J.H. Han, Y. Habata, C. Kang, J.S. Kim, Chem. Commun. 47 (2011) 51425144.

[75] O.G. Tsay, K.M. Lee, D.G. Churchill, New J. Chem. 36 (2012) 1949-1952.

[76] H. Wang, G. Zhou, X. Chen, Sens. Actuator B-Chem. 176 (2013) 698-703.

[77] K.M. Holmström, T. Finkel, Nat. Rev. Mol. Cell Biol. 15 (2014) 411-421. 
[78] L.A. Sena, N.S. Chandel, Mol. Cell 48 (2012) 158-167.

[79] P.C. Dedon, S.R. Tannenbaum, Arch. Biochem. Biophys. 423 (2004) 12-22.

[80] R.P. Patel, J. McAndrew, H. Sellak, C.R. White, H. Jo, B.A. Freeman, V.M. DarleyUsmar, Biochim. Biophys. Acta 1411 (1999) 385-400.

[81] L.E. McQuade, S.J. Lippard, Curr. Opin. Chem. Biol. 14 (2010) 43-49.

[82] X. Chen, X. Tian, I. Shin, J. Yoon, Chem. Soc. Rev. 40 (2011) 4783-4804.

[83] H.O. Steinberg, G. Brechtel, A. Johnson, N. Fineberg, A.D. Baron, J. Clin. Invest. 94 (1994) 1172.

[84] F. Murad, Angew. Chem. Int. Ed. 38 (1999) 1856-1868.

[85] C. Szabó, H. Ischiropoulos, R. Radi, Nat. Rev. Drug Discov. 6 (2007) 662-680.

[86] Z.J. Tonzetich, L.E. McQuade, S.J. Lippard, Inorg. Chem. 49 (2010) 6338-6348.

[87] L.E. McQuade, M.D. Pluth, S.J. Lippard, Inorg. Chem. 49 (2010) 8025-8033.

[88] S.A. Hilderbrand, S.J. Lippard, Inorg. Chem. 43 (2004) 5294-5301.

[89] K.J. Franz, N. Singh, B. Spingler, S.J. Lippard, Inorg. Chem. 39 (2000) 4081-4092.

[90] S.A. Hilderbrand, S.J. Lippard, Inorg. Chem. 43 (2004) 4674-4682.

[91] M.H. Lim, C. Kuang, S.J. Lippard, ChemBioChem 7 (2006) 1571-1576.

[92] M.H. Lim, S.J. Lippard, Acc. Chem. Res. 40 (2007) 41-51.

[93] H. Li, A. Wan, Analyst 140 (2015) 7129-7141.

[94] M.H. Lim, S.J. Lippard, Inorg. Chem. 43 (2004) 6366-6370.

[95] S.A. Hilderbrand, M.H. Lim, S.J. Lippard, J. Am. Chem. Soc. 126 (2004) 4972-4978.

[96] K. Tsuge, F. DeRosa, M.D. Lim, P.C. Ford, J. Am. Chem. Soc. 126 (2004) 6564-6565.

[97] M.H. Lim, B.A. Wong, W.H. Pitcock, D. Mokshagundam, M.H. Baik, S.J. Lippard, J. Am. Chem. Soc. 128 (2006) 14364-14373.

[98] M.H. Lim, D. Xu, S.J. Lippard, Nat. Chem. Biol. 2 (2006) 375-380.

[99] M.D. Pluth, M.R. Chan, L.E. McQuade, S.J. Lippard, Inorg. Chem. 50 (2011) 9385-9392.

[100] X. Hu, J. Wang, X. Zhu, D. Dong, X. Zhang, S. Wu, C. Duan, Chem. Commun. 47 (2011) 11507-11509.

[101] M.D. Pluth, L.E. McQuade, S.J. Lippard, Org. Lett. 12 (2010) 2318-2321.

[102] L.E. McQuade, S.J. Lippard, Inorg. Chem. 49 (2010) 7464-7471. 
[103] J. Ouyang, H. Hong, C. Shen, Y. Zhao, C. Ouyang, L. Dong, J. Zhu, Z. Guo, K. Zeng, J. Chen, Free Radical Biol. Med. 45 (2008) 1426-1436.

[104] B. Muthuraj, R. Deshmukh, V. Trivedi, P.K. Iyer, ACS Appl. Mater. Interfaces 6 (2014) 6562-6569.

[105] L. Tan, A. Wan, H. Li, Analyst 138 (2013) 879-886.

[106] N. Wilson, L.H. Mak, A. Cilibrizzi, A.D. Gee, N.J. Long, R. Woscholski, R. Vilar, Dalton Trans. 45 (2016) 18177-18182.

[107] L.E. McQuade, J. Ma, G. Lowe, A. Ghatpande, A. Gelperin, S.J. Lippard, Proc. Natl. Acad. Sci. USA 107 (2010) 8525-8530.

[108] M. Ghosh, N.M. van den Akker, K.A. Wijnands, M. Poeze, C. Weber, L.E. McQuade, M.D. Pluth, S.J. Lippard, M.J. Post, D.G. Molin, PloS One 8 (2013) e75331.

[109] M.H. Lim, S.J. Lippard, J. Am. Chem. Soc. 127 (2005) 12170-12171.

[110] B. Mondal, P. Kumar, P. Ghosh, A. Kalita, Chem. Commun. 47 (2011) 2964-2966.

[111] L.A. Juárez, A. Barba-Bon, A.M. Costero, R. Martínez-Máñez, F. Sancenón, M. Parra, P. Gaviña, M.C. Terencio, M.J. Alcaraz, Chem. Eur. J. 21 (2015) 15486-15490.

[112] J.M. Fukuto, A.S. Dutton, K.N. Houk, ChemBioChem 6 (2005) 612-619.

[113] M.L. Bullen, A.A. Miller, K.L. Andrews, J.C. Irvine, R.H. Ritchie, C.G. Sobey, B.K. Kemp-Harper, Antioxidants \& redox signaling 14 (2011) 1675-1686.

[114] P. Rivera-Fuentes, S.J. Lippard, Acc. Chem. Res. 48 (2015) 2927-2934.

[115] Z. Miao, S.B. King, Nitric Oxide 57 (2016) 1-14.

[116] U.P. Apfel, D. Buccella, J.J. Wilson, S.J. Lippard, Inorg. Chem. 52 (2013) 3285-3294.

[117] X. Sun, G. Kim, Y. Xu, J. Yoon, T.D. James, ChemPlusChem 81 (2016) 30-34.

[118] J. Rosenthal, S.J. Lippard, J. Am. Chem. Soc. 132 (2010) 5536-5537.

[119] Y. Zhou, K. Liu, J.Y. Li, Y. Fang, T.C. Zhao, C. Yao, Org. Lett. 13 (2011) 1290-1293.

[120] M.A. Michael, G. Pizzella, L. Yang, Y. Shi, T. Evangelou, D.T. Burke, Y. Zhang, J. Phys. Chem. Lett. 5 (2014) 1022-1026.

[121] Y. Zhou, Y.W. Yao, J.Y. Li, C. Yao, B.P. Lin, Sens. Actuator B-Chem. 174 (2012) 414420.

[122] A.T. Wrobel, T.C. Johnstone, A. Deliz Liang, S.J. Lippard, P. Rivera-Fuentes, J. Am. Chem. Soc. 136 (2014) 4697-4705.

[123] A. Loas, R.J. Radford, A.D. Liang, S.J. Lippard, Chem. Sci. 6 (2015) 4131-4140.

[124] L. Li, P. Rose, P.K. Moore, Annu. Rev. Pharmacol. Toxicol. 51 (2011) 169-187. 
[125] M. Strianese, C. Pellecchia, Coord. Chem. Rev. 318 (2016) 16-28.

[126] Z. Guo, G. Chen, G. Zeng, Z. Li, A. Chen, J. Wang, L. Jiang, Analyst 140 (2015) 17721786.

[127] F. Yu, X. Han, L. Chen, Chem. Commun. 50 (2014) 12234-12249.

[128] M.G. Choi, S. Cha, H. Lee, H.L. Jeon, S.K. Chang, Chem. Commun. 47 (2009) 73907392.

[129] K. Sasakura, K. Hanaoka, N. Shibuya, Y. Mikami, Y. Kimura, T. Komatsu, T. Ueno, T. Terai, H. Kimura, T. Nagano, J. Am. Chem. Soc. 133 (2011) 18003-18005.

[130] Y. Fu, Q.C. Feng, X.J. Jiang, H. Xu, M. Li, S.Q. Zang, Dalton Trans. 43 (2014) 58155822.

[131] Q. Meng, R. Zhang, H. Jia, X. Gao, C. Wang, Y. Shi, A.V. Everest-Dass, Z. Zhang, Talanta 143 (2015) 294-301.

[132] F. Hou, J. Cheng, P. Xi, F. Chen, L. Huang, G. Xie, Y. Shi, H. Liu, D. Bai, Z. Zeng, Dalton Trans. 41 (2012) 5799-5804.

[133] X. Cao, W. Lin, L. He, Org. Lett. 13 (2011) 4716-4719.

[134] F. Hou, L. Huang, P. Xi, J. Cheng, X. Zhao, G. Xie, Y. Shi, F. Cheng, X. Yao, D. Bai, Inorg. Chem. 51 (2012) 2454-2460.

[135] X. Wu, H. Li, Y. Kan, B. Yin, Dalton Trans. 42 (2013) 16302-16310.

[136] V.S. Lin, A.R. Lippert, C.J. Chang, Methods Enzymol. 554 (2015) 63-80. 